FONDAZIONE ENI ENRICO MATTEI

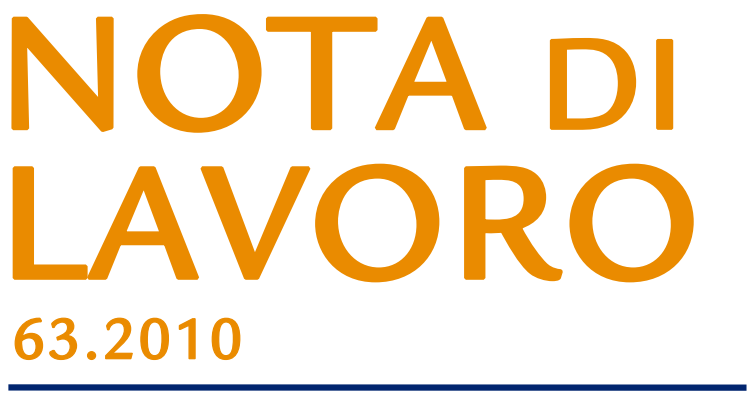

International Cooperation on Climate Change Adaptation from an Economic Perspective

By Kelly C. de Bruin, Environmental Economics and Natural Resources Group Wageningen University

Rob B. Dellink, Environmental Economics and Natural Resources Group, Wageningen University Richard S.J. Tol, Institute for Environmental Studies, Vrije Universiteit, Amsterdam, The Netherlands, Economic and Social Research Institute, Dublin, Ireland and Department of Spatial Economics, Vrije Universiteit, Amsterdam, The Netherlands 


\section{International Cooperation on Climate Change Adaptation from an Economic Perspective}

By Kelly C. de Bruin, Environmental Economics and Natural Resources Group Wageningen University

Rob B. Dellink, Environmental Economics and Natural Resources

Group, Wageningen University

Richard S.J. Tol, Institute for Environmental Studies, Vrije Universiteit, Amsterdam, The Netherlands, Economic and Social Research Institute, Dublin, Ireland and Department of Spatial Economics, Vrije Universiteit, Amsterdam, The Netherlands

\section{Summary}

This paper investigates the economic incentives of countries to cooperate on international adaptation financing. Adaptation is generally implicitly incorporated in the climate change damage functions as used in Integrated Assessment Models. We replace the implicit decision on adaptation with explicit adaptation in a multi-regional setting by using an adjusted RICE model. We show that making adaptation explicit will not affect the optimal mitigation path when adaptation is set at its optimal level. Sub-optimal adaptation will, however, change the optimal mitigation path. Furthermore this paper studies for different forms of cooperation what effects international adaptation transfers will have on (i) domestic adaptation and (ii) the optimal mitigation path. Adaptation transfers will fully crowd out domestic adaptation in a first best setting. Transfers will decrease overall mitigation in our numerical simulations. An analytical framework is used to analyse the most important mechanisms and a numerical model is used to assess the magnitude of effects.

Keywords: Climate Change, Adaptation Funding, Integrated Assessment Modeling

JEL Classification: H41, Q4, Q54

Address for correspondence:

Kelly C. de Bruin

Environmental Economics and Natural Resources Group

Wageningen University

Hollandseweg 1

6706KN Wageningen

The Netherlands

Phone: +31 317482362

Fax: +31317484933

E-mail: kelly.debruin@wur.nl 


\title{
International cooperation on climate change adaptation from an economic perspective
}

\author{
Kelly C. de Bruin ${ }^{\mathrm{a}}$, Rob B. Dellink ${ }^{\mathrm{b}}$ and Richard S.J. Tol ${ }^{\mathrm{c}, \mathrm{de}}$. \\ a Corresponding author, Environmental Economics and Natural Resources Group, Wageningen \\ University, Hollandseweg 1, 6706KN, Wageningen, The Netherlands. Telephone: + 31317482362 , \\ Fax: + 313174849 33, email: kelly.debruin@wur.nl . \\ b Environmental Economics and Natural Resources Group, Wageningen University \\ c Institute for Environmental Studies, Vrije Universiteit, Amsterdam, The Netherlands \\ d Economic and Social Research Institute, Dublin, Ireland \\ e Department of Spatial Economics, Vrije Universiteit, Amsterdam, The Netherlands
}

\begin{abstract}
This paper investigates the economic incentives of countries to cooperate on international adaptation financing. Adaptation is generally implicitly incorporated in the climate change damage functions as used in Integrated Assessment Models. We replace the implicit decision on adaptation with explicit adaptation in a multi-regional setting by using an adjusted RICE model. We show that making adaptation explicit will not affect the optimal mitigation path when adaptation is set at its optimal level. Sub-optimal adaptation will, however, change the optimal mitigation path. Furthermore this paper studies for different forms of cooperation what effects international adaptation transfers will have on (i) domestic adaptation and (ii) the optimal mitigation path. Adaptation transfers will fully crowd out domestic adaptation in a first best setting. Transfers will decrease overall mitigation in our numerical simulations. An analytical framework is used to analyse the most important mechanisms and a numerical model is used to assess the magnitude of effects.
\end{abstract}

JEL Classification: H41, Q4, Q54

Keywords: Climate change, Adaptation funding, Integrated Assessment Modeling 


\section{Introduction}

Climate policy comprises both adaptation and mitigation. Mitigation abates climate change by reducing emissions or capturing carbon. Adaptation involves adjusting behaviour and infrastructure to better fit the new climate, thereby reducing the damages from climate change or increasing the benefits of climate change. To set optimal policies, Integrated Assessments Models (IAMs) have been developed to study the full cause and effect chain of climate change. In many such models, the damages of climate change are monetised and can be compared with the costs of mitigation options. Thus a cost-benefit approach can be applied to study climate change and formulate optimal climate change policies.

The climate change damage functions used in these models, however, generally assume optimal adaptation and incorporate adaptation implicitly in the damage functions. This means that adaptation cannot be studied in itself as a decision variable, let alone in a suboptimal setting. To be able to better understand the role and importance of adapting, an economic assessment of the costs and benefits of adaptation, by making adaptation explicit in IAMs, is essential. In this context, de Bruin et al. (2009a) have introduced the concept of an "adaptation cost curve", that summarises the macroeconomic costs and impacts of adaptation efforts, and have subsequently adjusted the DICE model (Nordhaus and Boyer 2000), now called AD-DICE, to include an explicit adaptation choice variable. They find that when setting adaptation at its optimal level in the AD-DICE model, the results with respect to mitigation policies remain the same as in the original DICE model. This is obvious for the base case, as residual damage and adaptation costs are calibrated to the implicit optimum in DICE. However, the same result holds in sensitivity analyses (without re-calibration). That is, DICE's implicit assumptions on adaptation do not bias its policy advice on mitigation. The DICE model is, however, a global model, with one benevolent leader maximising the utility of the globe. In a multiregional setting there are numerous players who can choose to cooperate on climate change (in different degrees) or to act solely in self interest. The first aim of this paper is to analyse whether the results of de Bruin et al. (2009a) are valid in a multi-regional setting with various forms of cooperation.

Both the UNFCCC and IPCC WGIII TAR (IPCC, 2007) stress the role of financial transfers for the sake of mitigation as well as adaptation (e.g. in the form of an adaptation fund) as policy tools that can be used to build political support for international climate action. The topic of international adaptation financing, and which regions should receive funds from it and which should pay into it, has been discussed in recent literature (e.g. Burton et al. 2002, Bouwer and Aerts, 2006, Paavola and Adger, 2006; Dellink et al., 2009); Van Drunen et al. (2009) provide a systematic overview of existing and suggested financing mechanism. Especially in a policy setting adaptation funding has had a lot of attention, where it was an important topic of the recent UNFCCC meeting in Bali (UNFCCC, 2007) and an important point on the agenda for Copenhagen.

Also the effects of monetary transfers on the incentives to join a coalition have been studied (e.g. Chander and Tulkens, 1997; Barrett, 2001; Carraro et al., 2006; Nagashima et al., 2009; Bosetti et al., 2009). Furthermore, transfers have been introduced into IAMs such as the EPPA model (Jacoby et al., 2004) in the form of financial transfers and in the RICE model in the form of technological transfers (Yang and Nordhaus, 2006). To our knowledge the only instance where adaptation transfers are considered in an IAM setting is in Hof et al. (forthcoming), which looks at the feasibility of financing adaptation needs in developing regions through a tax on Clean Development Mechanism (CDM) projects. The second aim of this paper is therefore to study what effects adaptation transfers will have on (i) domestic adaptation and (ii) the optimal mitigation path.

To study our two objectives, we first present an analytical model of climate-economy interactions that focuses on the economic aspects of adaptation. We introduce adaptation costs and benefits in our model, and investigate the role that international financing of adaptation can play. Next, the AD-RICE model is presented, including its calibration to RICE. The 
numerical AD-RICE model is used to study the magnitude of the effects and to investigate questions that cannot be solved analytically. We look at three forms of cooperation; Nash (no cooperation), Climate cooperation (regional differences in climate change damages are considered) and Full cooperation (regional differences in income per capita are considered). We show for all forms of cooperation that when adaptation is assumed optimal, making adaptation implicit in the net damage function will not affect the mitigation results. We also show that if adaptation is not optimal, mitigation will be affected and adaptation and mitigation can compensate for suboptimal levels of each other. Note that we assume that adaptation efforts will only benefit the region where they are undertaken and there will be no spillover benefits or costs to other regions. Thus the optimal level of adaptation investments undertaken in a region by that region will not differ in the cooperative and non-cooperative case. We show that adaptation transfers will fully crowd out domestic adaptation expenditures in the equilibrium (where adaptation and mitigation are set at their optimal levels), but not necessarily when domestic adaptation is sub-optimal. Furthermore transfers will only take place in the cases of climate cooperation (running from low impact to high impact regions) and full cooperation (running from rich to poor regions). Our numerical model shows that emissions may increase slightly due to adaptation transfers.

This paper is structured as follows. The second section describes the simplified integrated assessment model we use. The third section presents our propositions. The fourth section describes the calibration of our numerical model (AD-RICE) and studies the magnitude of the effects found in section three. The final section concludes.

\section{An explicit model of adaptation}

In this section we describe a simple integrated assessment model, where economic growth and climate change are linked. We first introduce a basic model with implicit adaptation. In this model there is one control variable, namely mitigation $\left(\mu_{j, t}\right)$. We then develop a second model which includes a damage function with explicit adaptation. When adaptation is explicit, gross damages can be reduced through adaptation efforts. In this model there are two control variables; mitigation $\left(\mu_{j, t}\right)$ and adaptation $\left(P_{j, t}\right)$.We extend this model further to be able to include international adaptation transfers.

\subsection{The basic model}

For simplicity, we assume that there are 2 regions, $j=\mathrm{H}, \mathrm{D}$, although the main conclusions can easily be extended to more regions. We furthermore assume, without loss of generality, that each region is of the same size in terms of population and that populations are constant over time. Moreover all parameters are non-zero.

Regions produce output $Y_{j, t}$, which is given exogenously, causing emissions. Emissions are a linear function of output (with coefficient $\Omega_{j}$ ). Emissions can be reduced through mitigation efforts $\left(\mu_{j, t}\right)$. Thus net emissions depend on both output and mitigation:

$E_{j, t}=\Omega_{j} \cdot Y_{j, t}\left(1-\mu_{j, t}\right)$

Mitigation efforts come at a cost. The associated mitigation costs $\left(M C_{j, t}\right)$ are given as follows: 


$$
\frac{M C_{j, t}}{Y_{j, t}}=\theta_{1, j, t} \cdot \mu_{j, t}^{\theta_{2, j, t}}
$$

Net damages as percentage of GDP $\left(D_{j, t}\right)$ are caused by cumulative global emissions $\left(M_{t}\right)$ : $M_{t} \equiv\left(\sum_{s=1}^{t-1} \sum_{j=1}^{J} E_{j, s}\right)+M_{0}$; for simplicity we assume that this is a linear relationship described as follows ${ }^{1}$ :

$$
\frac{D_{j, t}}{Y_{j, t}}=\varphi_{j} \cdot M_{t}
$$

In our model output equals (national) income and regions can consume their output minus the sum of net damages of climate change and the costs of mitigation as follows:

$$
C_{j, t}=Y_{j, t}-D_{j, t}-M C_{j, t}
$$

Finally regional utility $\left(U_{j}\right)$ is derived from the discounted sum of consumption in each period over the planning horizon $T$ (as we have a constant population, this implicitly maximises consumption per capita). Consumption is discounted over time using a discount factor $\left(\rho_{t}\right)$ :

$$
U_{j}=\sum_{t=1}^{T} \rho_{t} \cdot\left(C_{j, t}\right)
$$

The regional utilities are weighted to create a global social welfare function (SWF):

$$
S W F=v_{j} \sum_{j=1}^{J} U_{j}
$$

Maximising SWF involves choosing optimal values for the mitigation and adaptation levels, denoted by $\mu_{j, t}^{*}$ and $P_{j, t}^{*}$, respectively. Using different regional utility weights yields different solutions; this will be explored in more detail in Section 2.3.

\subsection{Adaptation}

We now introduce adaptation into our model. The damage equation (3) with implicit adaptation is replaced by the more elaborate system of equations (7)-(9) and income equation (11) replaces equation (4); the other equations remain unchanged.

We assume gross damages $\left(G D_{j, t}\right)$, i.e. potential climate change damages without adapting, have a linear relationship to cumulative emissions:

\footnotetext{
${ }^{1}$ Dellink et al. (forthcoming) show that a linear relationship is a reasonable approximation for this relationship.
} 


$$
\frac{G D_{j, t}}{Y_{j, t}}=\omega_{j} \cdot M_{t}
$$

Residual damages $\left(R D_{j, t}\right)$ are a function of adaptation $\left(P_{j, t}\right)$ and gross damages, where

$0 \leq P_{j, t} \leq 1$ represents the fraction by which gross damages are reduced:

$R D_{j, t}=\left(1-P_{j, t}\right) \cdot G D_{j, t}$.

Equation (8) shows that regional adaptation $P_{j, t}$ will only decrease gross damages in the own region, i.e. we assume there are no spillovers (externalities) from adaptation to other regions. Adaptation costs $\left(P C_{j, t}\right)$ are given by:

$$
\frac{P C_{j, t}}{Y_{j, t}}=\gamma_{1, j} \cdot P_{j, t}^{\gamma_{2, j}}
$$

As the damage function in the base model implicitly assumed optimal adaptation $P_{j, t}^{*}$, it follows that $\frac{D_{j, t}}{Y_{j, t}} \equiv R D_{j, t}\left(P_{j, t}^{*}\right)+P C_{j, t}\left(P_{j, t}^{*}\right)$, where the asterix indicates the optimal level.

Consumption is still given as output minus all climate change costs:

$$
C_{j, t}=Y_{j, t}-R D_{j, t}-P C_{j, t}-M C_{j, t} \text {. }
$$

\subsection{Adaptation transfers}

We now introduce an adaptation fund to our model. Firstly we define region $D$ as the donor region and region $H$ as the host region. An adaptation transfer is financed from the consumption function of the donor region. Hence for region $D$ we augment the income equation (11) and replace it by

$$
C_{D, t}=Y_{D, t}-R D_{D, t}-P C_{D, t}-M C_{D, t}-T A_{t} \text {, }
$$

where $T A_{t}$ is the financial transfer for adaptation from region $D$ to region $H$.

We assume that this transfer will solely be used for adaptation purposes in region $H$. Hence adaptation cost equation (9) will be replaced in the host region by

$$
\frac{P C_{H, t}+T A_{t}}{Y_{H, t}}=\gamma_{1, H} \cdot P_{H, t}^{\gamma_{2, H}} \text {. }
$$

A drawback of the simple utility function (5) is that utility increases linearly with the income level, and thus marginal utility is constant in income and consumption. This affects the analysis when comparing countries with different income levels. To be able to capture the differences in marginal utility across regions we replace the utility function in the base model with one that uses a log function over consumption. This entails that the marginal effect of consumption increases on utility are lower when consumption is high than when it is low. Equation (5) is replaced by 
$U_{j}=\sum_{t=1}^{T} \rho_{t} \cdot \ln \left(C_{j, t}\right)$

This model allows us to investigate 3 cooperation scenarios:

i) Nash (no cooperation). In the uncooperative Nash case each region optimises its own utility taking the emissions of the other regions as given. The social welfare function weights are then the inverse of marginal utility $\frac{1}{C_{j, t}}$ yielding the competitive solution (Negishi 1960). In this case the shadow prices of capital in all regions are equalised and monetary transfers will not increase social welfare: any welfare increase from higher income in the host region will be matched exactly by an equivalent welfare loss in the donor region.

ii) Climate cooperation: differences in climate change impacts are considered. In this case, the social welfare function weights are given by the inverse marginal utility of income before climate change damages are subtracted, i.e. $\frac{1}{Y_{j, t}}$. In this case shadow prices are equalised when there are no damages from climate change. ${ }^{2}$ Monetary transfers will thus only be desirable from a social welfare perspective if damages among regions are unequal: compensation of damages in a high impact region by a low impact region will boost global welfare.

iii) Full cooperation: differences in income are considered. In the case of full cooperation, all regions have the same welfare weight. In this case summed utility of all regions is maximised, shadow prices will only be equalised across countries if consumption levels are equal across countries and monetary transfers will increase social welfare if they flow from a high income region to a low income region (this depends on the assumption that marginal utility decreases in income levels).

\section{Adaptation-mitigation interactions and the role of adaptation financing}

In this section we shortly discuss the key analytical insights obtained from each of our model settings presented in Section 2. These insights are summarised in a series of propositions. The formal results are given in Appendix A (base model) and Appendix B (model with transfers) and proofs are given in Appendix C.

\subsection{Optimal levels of adaptation and mitigation}

First, solving our base model (as discussed in 2.1) using the Nash cooperation scenario, we can gain insights in the drivers of the control variables. The optimal level of mitigation with implicit adaptation equals ${ }^{3}$ :

2 This is because this weight will result in the competitive equilibrium in the case of no damages of climate change.

3 Note that we assume that both regions experience positive gross damages from climate change, this is the case for most regions in the world, especially in the longer term. Some regions may, however, experience gross benefits from climate change. In our numerical AD-RICE model we include this possibility and model adaptation in such a way that it increases net gross benefits of climate change and decreases gross damages (see appendix). Here we focus on the case of gross damages, where adaptation can decrease gross damages to residual damages. 
$\mu_{j, t}^{*}=\left(\frac{\sum_{s=t+1}^{T}\left(\varphi_{j} \cdot Y_{j, s} \cdot \rho_{s}\right) \cdot \Omega_{j}}{\theta_{2, j, t} \cdot \theta_{1, j, t}}\right)^{\frac{1}{\theta_{2, j, t}-1}}$.

This result is intuitive: mitigation efforts increase as discounted value of future climate change damages increases $\left(\varphi_{j} \cdot Y_{j, s} \cdot \rho_{s}\right)$ and as the production emission coefficient increases $\left(\Omega_{j}\right)$. Together, these two elements determine the effectiveness of mitigation through a stream of reduced damages. Furthermore, the level of mitigation effort decreases as the cost parameters of mitigation increase $\left(\theta_{2, j, t}, \theta_{1, j, t}\right)$.

Second, when including an explicit adaptation control variable (i.e. using the model with explicit adaptation from section 2.2), the optimal level of adaptation is as follows:

$P_{j, t}^{*}=\left(\frac{\omega_{j} \cdot M_{t}}{\gamma_{2, j} \cdot \gamma_{1, j}}\right)^{\frac{1}{\gamma_{2, j}-1}}$.

The optimal level of adaptation thus increases when the gross damages increase $\left(\omega_{j} \cdot M_{t}\right)$ and decreases when the adaptation costs coefficients $\left(\gamma_{2, j}, \gamma_{1, j}\right)$ increase. As with mitigation, higher damages, relative to the marginal adaptation costs, make adaptation more effective and hence increase its optimal level.

The associated optimal level of mitigation with explicit adaptation is:

$\mu_{j, t}^{*}=\left(\frac{\sum_{s=t+1}^{T}\left(\omega_{j} \cdot Y_{j, s} \cdot\left(1-P_{j, s}^{*}\right) \cdot \rho_{s}\right) \cdot \Omega_{j}}{\theta_{2, j, t} \cdot \theta_{1, j, t}}\right)^{\frac{1}{\theta_{2, j, t}-1}}$.

The intuition of these results remains unchanged: the level of mitigation effort decreases as the cost parameters of mitigation $\left(\theta_{2, j, t}, \theta_{1, j, t}\right)$ increase and increases as discounted future climate change damages $\left(\omega_{j} \cdot Y_{j, s} \cdot\left(1-P_{j, s}^{*}\right) \cdot \rho_{s}\right)$ and the production emission coefficient $\left(\Omega_{j}\right)$ increase. What is new in equation (17) is that future benefits are now a function of adaptation levels. As future adaptation increases, the benefits of mitigation and thus the optimal level of mitigation decreases.

\subsection{Implicit versus explicit adaptation}

By comparing the model with explicit adaptation with the base model, we can investigate what effect making adaptation explicit will have. This is motivated from the fact that in most models of climate change adaptation is assumed implicit. When comparing explicit and implicit adaptation we only look at the Nash solution, i.e. we solve the optimisation problem for one region given the emissions of other regions. The results will hold for all scenarios given the regional characteristics of adaptation, i.e. the lack of international externalities.

Proposition 1. Making adaption explicit in the optimum will have no effect on the optimal levels of mitigation. 
This proposition is based on the idea that once you assume that adaptation will be set at its optimal level in the future, you need not consider adaptation explicitly. This is because adaptation, when set at its optimal level, can be expressed exogenously and making it explicit will not change the optimal level of adaptation and thus also not the resulting mitigation level. Furthermore, adaptation is a flow variable only; and there are no externalities in adaptation. While, obviously, this proposition hinges on the assumption that implicit adaptation levels are optimal, it conveys an important policy message: mitigation results from Integrated Assessment Models that are based on an implicit treatment of adaptation, i.e. the vast majority of models presented in the literature and for instance in the IPCC assessments, cannot be deemed as biased in their mitigation recommendations. Where de Bruin et al. (2009a) stress this same result from a global perspective, Proposition 1 extends this to the multi-regional specification.

\subsection{Adaptation transfers}

To obtain insights in the role of adaptation transfers, we applied our model that includes transfers as introduced in Section 2.3.

\section{Proposition 2a. Foreign adaptation funding fully crowds out domestic adaptation expenditures in the optimum.}

When total adaptation expenditures (host and donor) in the host region are set at their domestic optimal levels, the host region will have no incentives to increase its level of adaptation. Any inflows of financing for adaptation will therefore crowd out host adaptation expenditures, as the funds can be spend more effectively on other activities. While this is a quite general result, there are potentially relevant feedback effects that are not present in our model. For instance, a higher consumption level will not imply higher emissions, and thus the additional resources can be used without distorting the climate system.

Proposition 2b. Foreign adaptation funding is only effective (i.e. increases total adaptation efforts in the host region) if total adaptation expenditures (incl. received transfers) are below or equal to the domestic (host) optimum.

Due to the absence of externalities of adaptation, i.e. adaptation benefits are only local; the host region will not have an incentive to increase the total level of adaptation expenditure in its region above the domestic optimal level. If the host region receives foreign adaptation funding, it will only not decrease its level of adaptation expenditures if the total level remains below or equal to the domestic (host) optimal level. It is easy to see that due to the local nature of adaptation this will be the case for all cooperation scenarios.

Proposition 3a. Adaptation transfers will not take place in the competitive Nash equilibrium.

This proposition is intuitive; as there are no international spillovers from adaptation back to the donor region, it will never have the incentive to fund adaptation expenditures in the host region when it acts solely in self interest.

Proposition 3b. Adaptation transfers will be positive in the case of climate cooperation when the climate change impacts are higher in the host country than in the donor country.

In the case of climate change cooperation, low impact regions want to compensate high impact regions. An adaptation transfer can give low impact regions a means of compensating high impact regions, thereby exploiting the higher welfare effect this transfer will have. Note 
that this transfer crowds out adaptation in the high impact region (proposition 2a). The transfer compensates the high impact region which is beneficial as it reduces damages and therefore also the need for emission reduction.

Proposition 3c. Adaptation transfers will take place in the case of full cooperation when the level of consumption is lower in the host country than in the donor country.

When global utility is maximised, due to decreasing marginal utility, high income regions will want to compensate low income regions. Through adaptation transfers they are able to do so. Thus global welfare will increase as transfers run from low marginal utility to high marginal utility regions. Note this transfer crowds out adaptation in the low income region (proposition 2a). The transfer is used to compensate for differences in income.

None of our cooperation scenarios fully reflect what is likely to happen in the real world. They do, however, reflect the three main motivations behind the behaviour of regions when cooperating on climate change. Firstly, regions naturally are concerned about their own wellbeing. This is reflected in the Nash scenario. Secondly, when regions cooperate concerning climate change, they will want to compensate those most affected by climate change, this is reflected in the climate cooperation scenario. Thirdly, regions also consider the level of income in regions when cooperating. Regions generally have some, though low, incentives to compensate low income regions. This is reflected in the full cooperation scenario. In a real world context, motivations will lie somewhere in between these three extremes and will also likely depend on a region's historical responsibility in contributing to the climate change problem.

The effect of transfers on mitigation is too complex to study analytically. To illustrate the complexity of the issue, we shortly discuss some of the mechanisms at work in relationship between adaptation transfers and mitigation levels. Consider the case of climate cooperation where funds are transferred to some high-impact region $H$ by a low-impact region $D$ for the purpose of adaptation. Due to increased adaptation in region $H$, region $H$ will have lower residual damages and thus more funds for other expenditures. Region $H$ can spend these funds on consumption or on mitigation, thereby decreasing emissions or invest in capital, which increases future production and thus also emissions. ${ }^{4}$ Region $D$ now has fewer funds to invest in mitigation or capital but has a new mechanism by which to compensate region $H$ for the effects of climate change. Thus region $D$ can use adaptation transfers instead of mitigation to assist region $H$, thus reducing the need for $D$ to compensate for damages through a higher level of mitigation. Consequently, the social planner will trade-off the benefits and costs of mitigating versus financing adaptation. The final result of these various mechanisms is unclear a priori, and by applying our numerical model we can get a better understanding of the net result, which will be done in the next section.

\section{Numerical results}

The previous section provides several general insights using a simple model. We now apply our numerical AD-RICE model to gain insights into the magnitude of the mechanisms discussed in section 3 and to unravel secondary mechanisms that could not be studied analytically due to the large complexities involved. We first give a short description of the model and then discuss the results.

\footnotetext{
${ }^{4}$ Note that such investment in capital is not present in our stylised analytical model.
} 


\subsection{AD-RICE model}

The AD-RICE model incorporates adaptation into the RICE model ${ }^{5}$, using the same method as employed in de Bruin et al. (2009a), i.e. by calibrating an adaptation cost curve that describes the marginal costs of adaptation efforts, analogous to a marginal abatement cost curve as often used for mitigation efforts. The full model is given in Appendix D, where the adaptation components are described in equations A.37-A.39. RICE is a regional version of the Dynamic Integrated Climate and Economy model. It consists of 13 regions: Japan, USA, Europe $^{6}$, Other High Income countries $(\mathrm{OHI})^{7}$, High Income Oil exporting regions $(\mathrm{HIO})^{8}$, Middle Income countries (MI) ${ }^{9}$, Russia, Low-Middle income countries (LMI) ${ }^{10}$, Eastern Europe (EE), Low Income countries (LI) ${ }^{11}$, China, India and Africa ${ }^{12}$.

The AD-RICE model is calibrated such that it best replicates the results of the optimal control scenario of the original RICE model when adaptation is assumed to be at its optimal level throughout the model horizon. To this end regional adaptation cost curves are constructed such that the discounted squared difference between net damages $\left(D_{t, j}\right)$ in the original RICE and net damages $\left(R D_{t, j}+P C_{t, j}\right)$ in AD-RICE is minimised. It is also assumed that adaptation is set at an optimal level at each point in time. We calibrate the parameters of the adaptation cost function and the gross damage function. The calibrated parameter values of AD-RICE are given in Appendix 2. Three regions (EE, OHI and Russia) have been excluded from the calibration procedure for the adaptation cost curves as they have very low, near zero, net benefits from climate change. For these regions we assume that no adaptation will take place as the impacts are so close to zero. Adaptation costs curves are drawn for the remaining 10 regions in Figure 1, where the $\mathrm{x}$-axis shows the level of adaptation as fraction of gross damages reduced and the $y$-axis shows the associated costs as a fraction of output. The line denominated as GLOBAL has been added and represents the AD-DICE2007 (de Bruin et al. $2009 \mathrm{~b}$ ) global adaptation cost curve. As can be seen the adaptation costs in the different regions vary widely. Especially India, Africa and Low Income countries have high adaptation costs, whereas Japan, China and the USA have relatively low adaptation costs.

\footnotetext{
${ }^{5}$ We use the RICE99 model as available online.

${ }^{6}$ Austria, Belgium, Denmark, Finland, France, Germany, Greece, Greenland, Iceland, Ireland, Italy, Liechtenstein, Luxembourg, Netherlands, Norway, Portugal, Spain, Sweden, Switzerland, and the United Kingdom

${ }^{7}$ Includes Australia, Canada, New Zealand, Singapore, Israel, and rich island states

${ }^{8}$ Includes Bahrain, Brunei, Kuwait, Libya, Oman, Qatar, Saudi Arabia, and UAE.

${ }^{9}$ Includes Argentina, Brazil, Korea, and Malaysia.

${ }^{10}$ Includes Mexico, South Africa, Thailand, most Latin American states, and many Caribbean states.

${ }^{11}$ Includes Egypt, Indonesia, Iraq, Pakistan and many Asian states.

${ }^{12}$ Includes all sub Saharan African countries, except Namibia and South Africa
} 


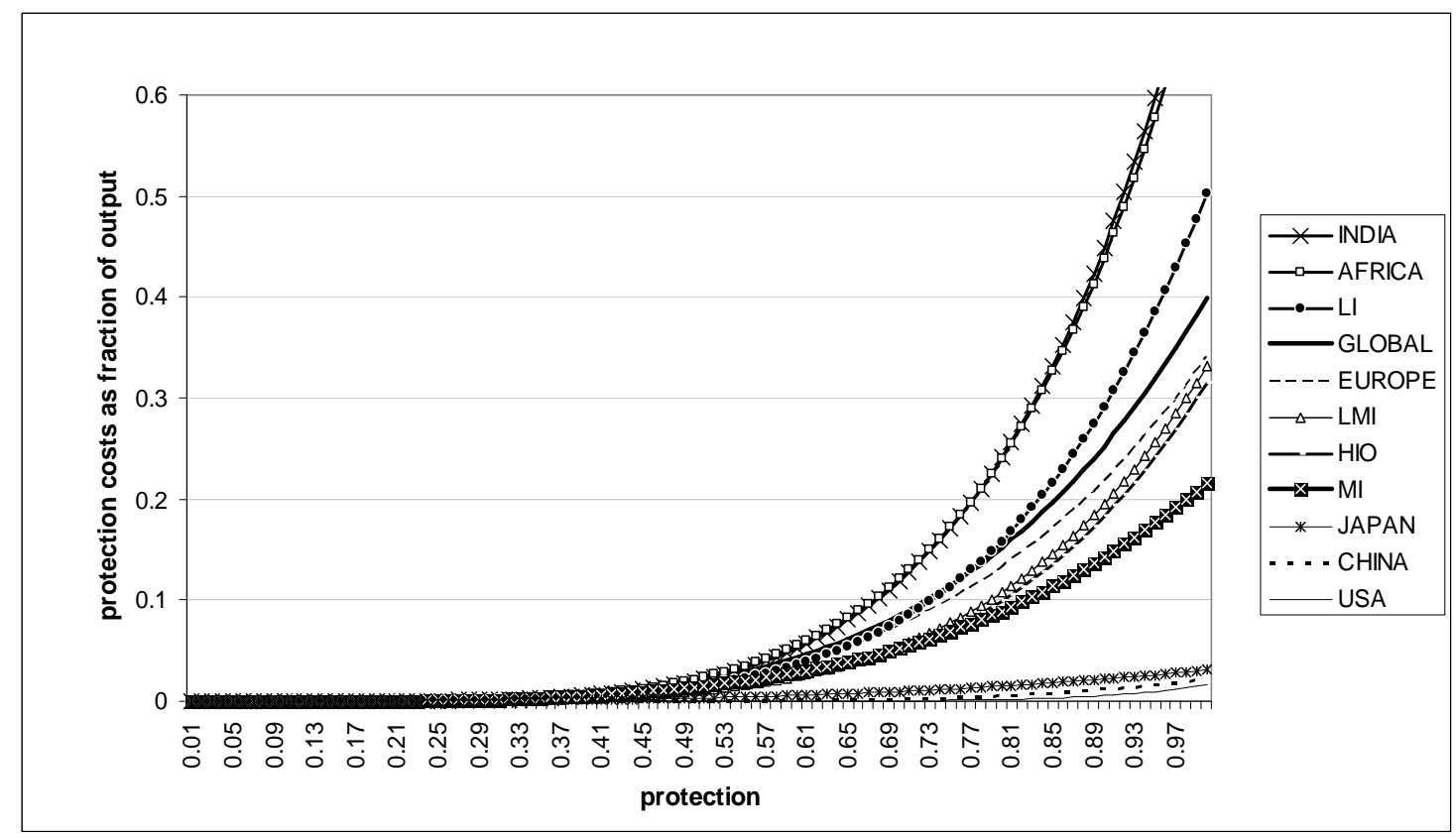

Figure 1: Adaptation costs curves implicit in the RICE model.

\subsection{Explicit versus implicit adaptation}

Figure 2 shows the optimal emissions path for our three cooperation scenarios (Nash, climate cooperation and full cooperation) with optimal adaptation and without adaptation. When adaptation is not possible, more mitigation is undertaken and emissions are lower. We also see that in the Nash solution, because there is no cooperation, sub-optimal adaptation has little effect on the optimal mitigation path. In the cooperation solutions sub-optimal adaptation has a greater effect as each region not only considers that it itself cannot adapt but also the welfare loss from the fact that the other regions cannot adapt. The negative externalities of emissions are much larger when adaptation is not possible inducing regions to mitigate more when cooperating. 


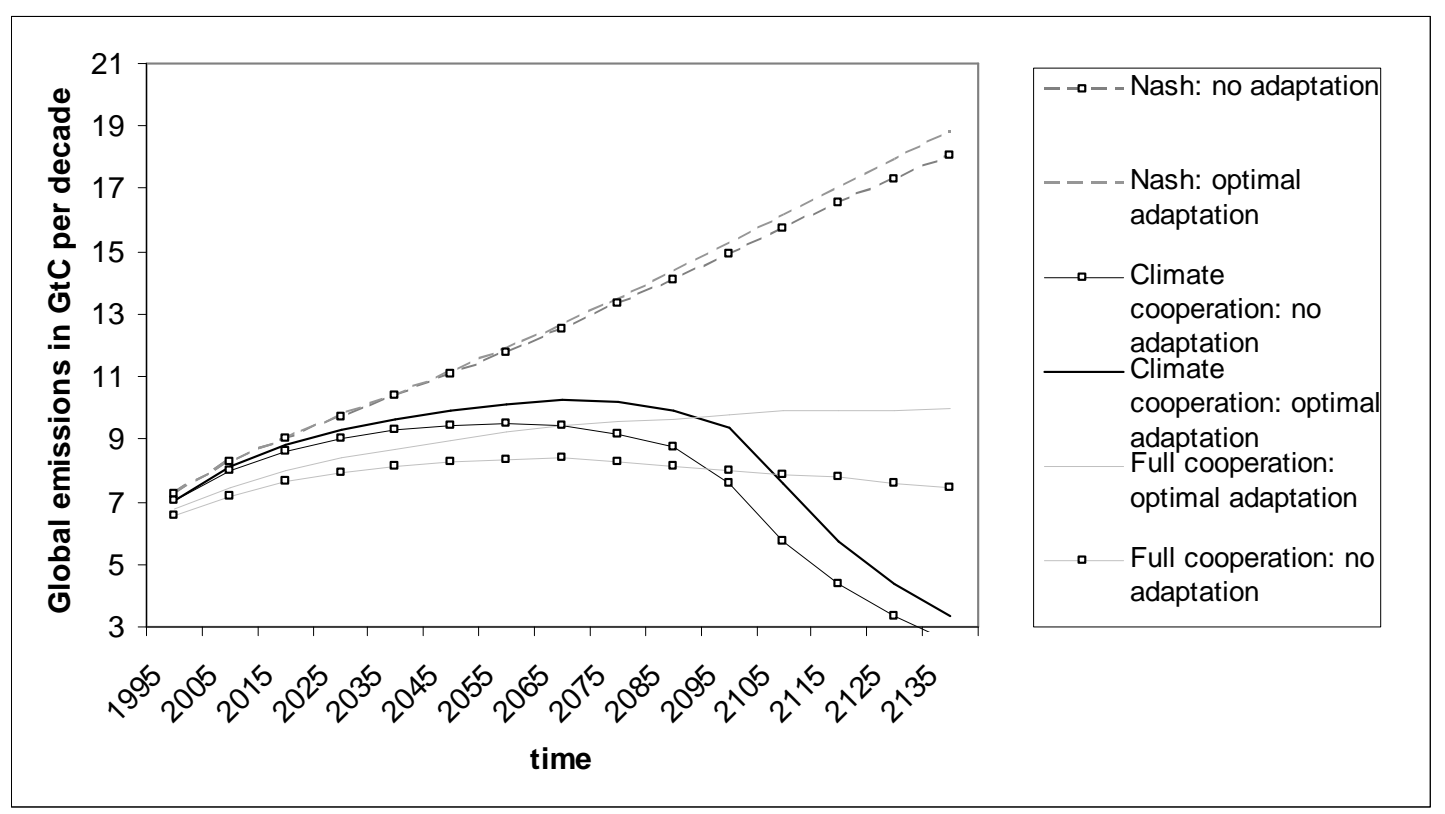

Figure 2: Optimal emissions paths for the three cooperation scenarios (Nash, climate cooperation and full cooperation) with optimal adaptation and without adaptation.

\subsection{Adaptation transfers}

In Section 3.3 we showed that financial transfers to fund adaptation in other regions will only take place in the cooperative cases. Here we use our numerical model to investigate the adaptation transfer magnitudes and directions in the more elaborate setting with multiple heterogeneous regions. ${ }^{13}$ Comparing the scenarios can give us an idea of which regions, according to this model, should receive (give) funding based on their relatively high damages and which should receive (give) based on their relatively low incomes.

In the case of climate cooperation, transfers will flow from low impact to high impact regions as shown in the previous section. We look at two cases; in the first case adaptation is set at its optimal level, in the second case adaptation expenses is limited in developing countries ${ }^{14}$, by assuming adaptation expenditures cannot be more than half of what would be optimal. We do this as it does not seem likely that optimal adaptation will be attainable in the real world, especially so for developing regions (cf. de Bruin and Dellink, 2009). In Figure 3 the total amount of adaptation funding is given over time for the climate cooperation case. In the case of optimal adaptation, the small levels of financing arise because of the steeply increasing adaptation costs, when adaptation is set at its locally optimal level, compensating for differences in climate impacts through financing of additional adaptation will be quite costly. In the case of limited adaptation in developing countries, transfers will be larger, as more cost-effective adaptation options are unused. The amount of funding increases sharply over time. Figure 4 presents the regional shares in the adaptation for the host and donor regions for the case of optimal and limited adaptation in developing regions. The total amount of funding from donors equates the total amount of funding received by hosts. In the case of

\footnotetext{
${ }^{13}$ Clearly, our specification of international cooperation is too stylised to be able to provide numerical results that can be used for policy recommendations. Our aim is merely to understand the magnitude and direction of flows using our two cooperation scenarios. Clearly, this setting abstracts from issues such as historical responsibility for climate change, and cannot be viewed as a policy recommendation ${ }^{14}$ We categorise HIO, MI, LMI, LI, China, India and Africa as developing regions.
} 
optimal adaptation only Russia and China provide funding. Although the two donors of adaptation financing may seem counter-intuitive at first sight, their profile fits the solution concept used: income differences are irrelevant except for damages caused by climate change. Thus, these two regions, that are expected to have relatively low damage levels, will compensate regions that are hit more severely by climate change. When adaptation in developing countries is limited, more funding needs to be provided, and our simulations show that Russia, Eastern Europe, Other high income countries and China are the donors in the case of climate cooperation. Again, these are the regions with the lowest damages (or highest benefits) from climate change. The most vulnerable regions India, Low income countries, Low middle income countries, Africa, and Middle income countries receive the most funding.

Figure 3: Total adaptation transfers to regions in percentage of global GDP for the case of climate cooperation.
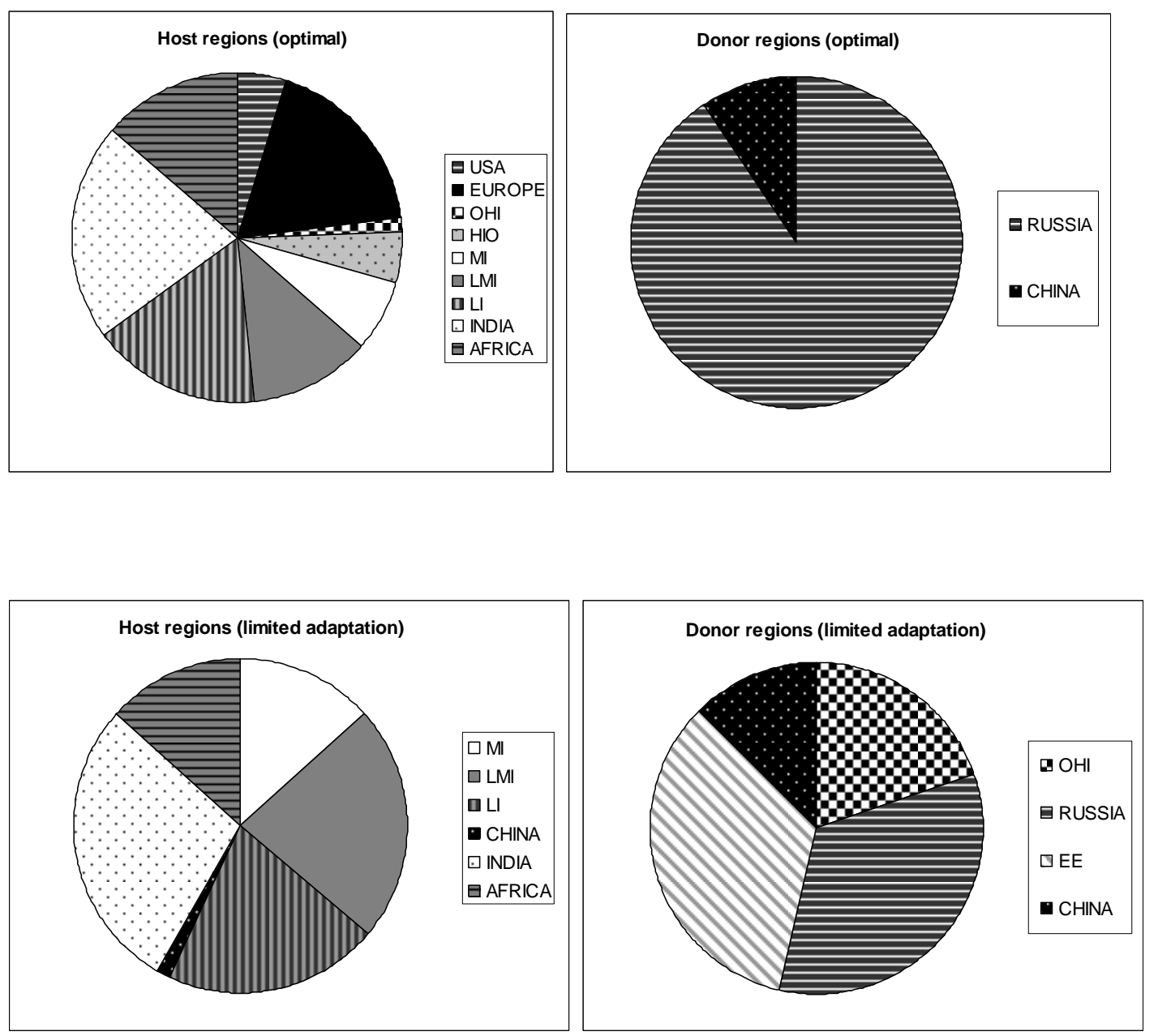

Figure 4: Regional composition of adaptation funding for the case of climate cooperation with optimal adaptation and with adaptation expenditures limited to $50 \%$ of optimal, where host regions receive funding and donor regions give funding ${ }^{15}$.

Figure 5 and 6 show the adaptation transfers in the case of full cooperation over time. Introducing an adaptation fund gives regions a way to transfer money in order to equalise marginal utilities across regions. Because in this setting adaptation funding is not only

${ }^{15}$ Note that regions with a share of less than $1 \%$ in adaptation funding are omitted from the figure. 
compensating for climate change damages, but is also used as a development fund, both the magnitude of the flows (cf. Figures 5 and 3 ) and the division between hosts and donors is radically different (cf. Figures 6 and 4). In the full cooperation case we see that the richest regions, notably USA, Japan and Other High Income, transfer to the poorest regions, with a large part flowing to Africa. Once again these results confirm our insights of Section 3. Furthermore, limiting adaptation increases transfers but this increase is very small relative to the size of the transfers under optimal adaptation. We see thus that there are huge differences between the climate cooperation and full cooperation solutions. As Nordhaus and Yang (2006) mention, the full cooperation case is often used to investigate climate change cooperation as it easy to implement and justify. In the full cooperation scenario funds will stream from high income to low income regions due to differences in marginal utility. One can think of this as interconnected reservoirs with different water levels. When the connectors are opened, water will flow from high to low levels. An adaptation transfer gives regions a way to open these connectors. Applying a full cooperation scenario can therefore be misleading from the perspective of a focused climate policy impact analysis as it incorporates development assistance as well as climate change cooperation.

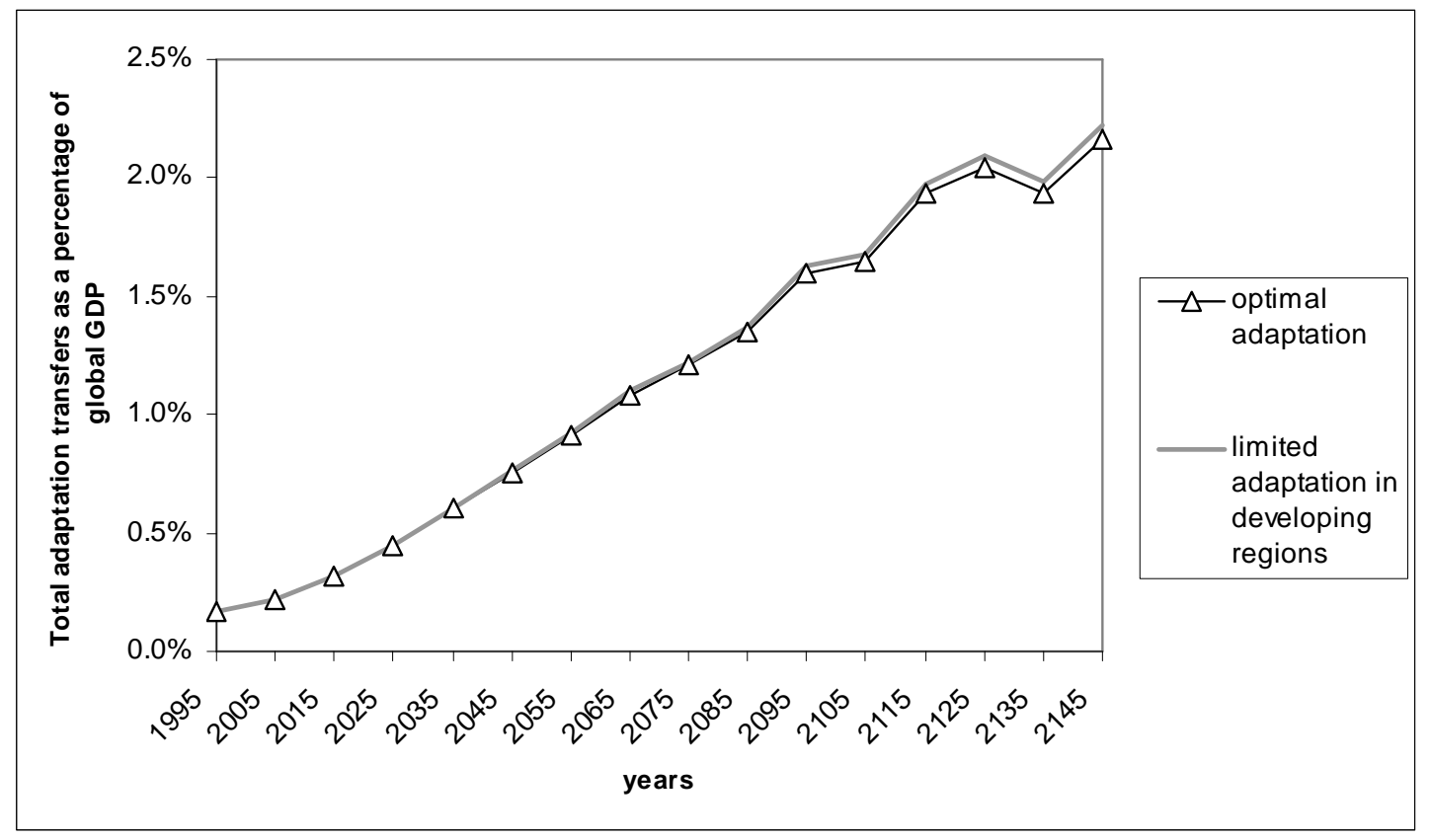

Figure 5: Total adaptation transfers to regions in percentage of global GDP for the case of full cooperation.
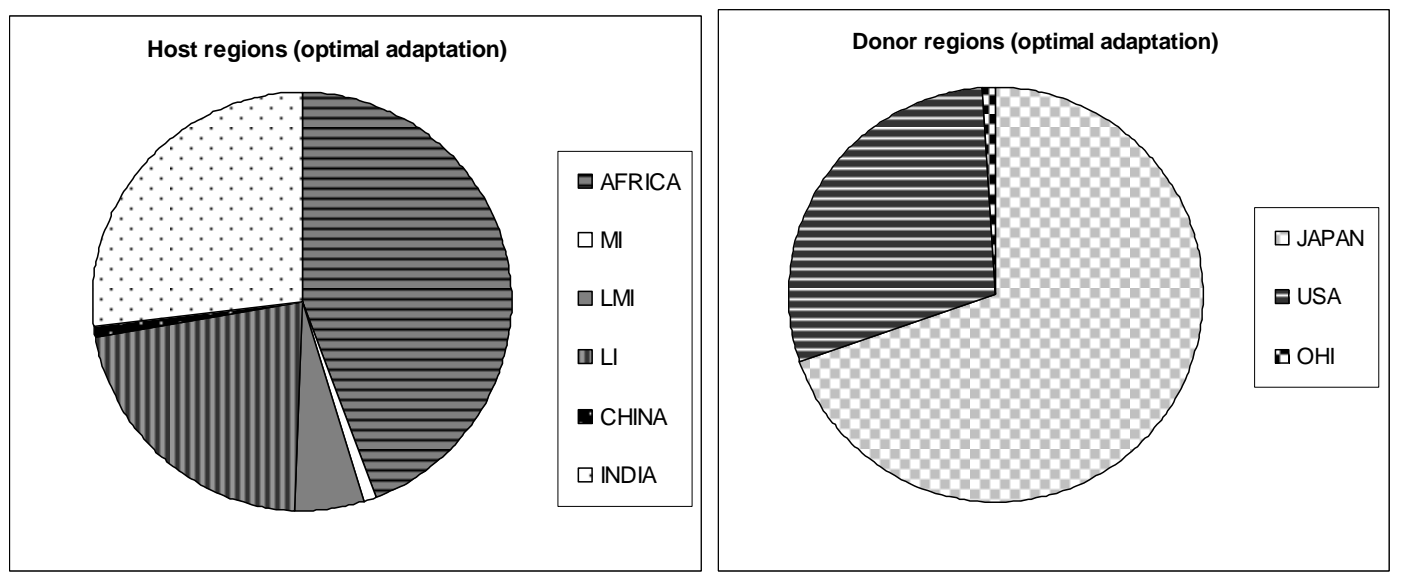

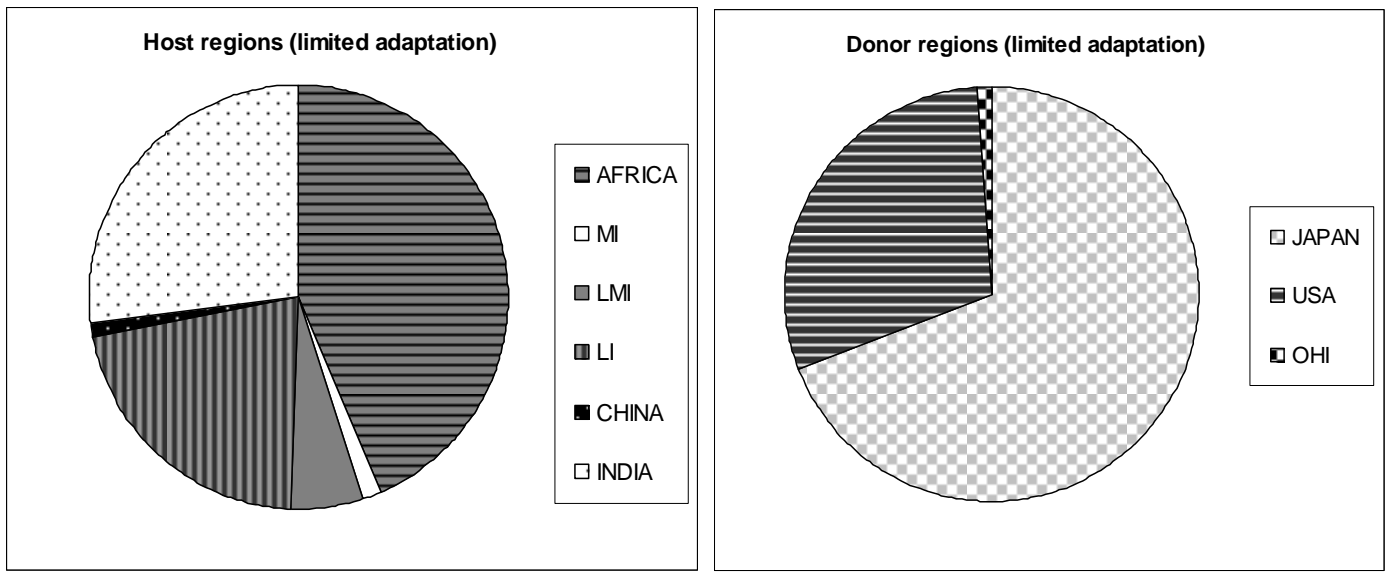

Figure 6: Regional composition of adaptation funding for the case of full cooperation with optimal adaptation and with adaptation expenditures limited to 50\% of optimal, where host regions receive funding and donor regions give funding

\subsection{Transfers and mitigation}

Our complex applied model can also be used to investigate a number of mechanisms that could not be dealt with in the analytical model. One important issue is that of the effect of transfers on mitigation.

The overall effect of transfers on mitigation can be seen in Figure 7 for the two cooperative solutions. We see that emissions increase and thus mitigation decreases considerably in the case of full cooperation. In the case of climate cooperation emissions are almost the same, implying overlapping lines in the figure. It is logical that the effects are higher in the full cooperation scenario, as the transfers too are much higher compared to the climate cooperation scenario. The results for the individual regions (omitted here) indicate that emissions increase in all regions when adaptation transfers are introduced except in Africa in the case of full cooperation. As transfers grow, so does the amount of disposable funds. It is most beneficial for Africa to spend these funds on mitigation (even though there is increased adaptation) as opposed to other investments, this also due to the externalities of mitigation. 


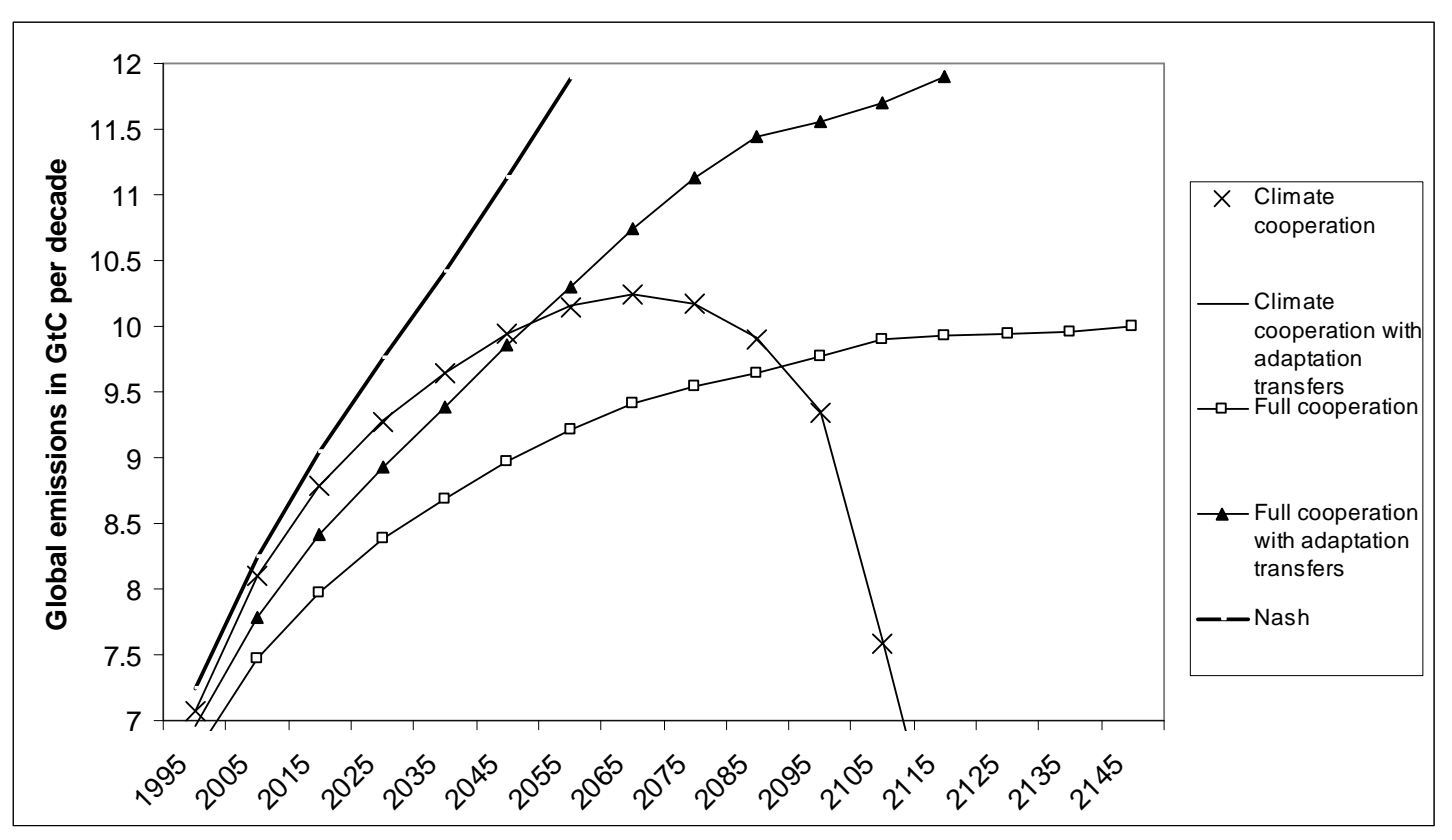

Figure 7: Optimal emissions paths for the 3 solution concept (Nash, climate cooperation and full cooperation) with and without transfers (with optimal adaptation).

\section{Conclusions}

This paper investigated two main issues; firstly what is the effect of making adaptation explicit in an integrated assessment modeling framework in a multi regional setting. We look at three forms of cooperation between regions: Nash (no cooperation), Climate cooperation (regional differences in climate change damages are considered) and Full cooperation (regional differences in income per capita are considered). We find that explicitly including adaptation as a control option, will not affect the resulting mitigation policy outcomes in a first best world where adaptation is set at its optimal level, i.e. policies of mitigation and adaptation are separable in a multi-regional first best setting. Making adaptation explicit makes it possible, however, to study other states of the world. When policies are not optimal, mitigation and adaptation can compensate for sub-optimal levels of each other. Here, adaptation and mitigation are not separable and sub-optimal adaptation will affect the optimal mitigation path. Our numerical model (AD-RICE) shows that the mitigation path can be affected considerably. We conclude that the assumption of optimal implicit adaptation needs to be reconsidered to create sound mitigation policy conclusions.

Secondly this paper aimed to answer questions concerning adaptation transfers. For each form of cooperation, we study if transfers will take place and what effects adaptation transfers will have on (i) domestic adaptation and (ii) the optimal mitigation path. We find that in a first best world foreign adaptation funding will crowd out domestic adaptation expenditures. When ensuring that crowding out is not possible we see that adaptation transfers will run from low climate change impact regions to high climate change impact regions. In the case of full cooperation adaptation transfers run from high income to low income regions and serve as a form of development assistance, attempting to equalise consumption per capita over regions. Transfers are thus much larger in full cooperation than in climate cooperation. We also see that transfers increase tremendously when adaptation in limited in developing regions. The magnitude and direction of transfers are very different in the different 
forms of cooperation. When setting policies, one needs to carefully understand the distributional effects and assumptions underlying modelling results. The overall effect that adaptation transfers may have on mitigation is dominated by several mechanisms. A transfer will increase the budget of the receiving region which may decrease emissions (when more is invested in mitigation) or increase emissions (when more is invested in capital). A transfer will decrease the budget of donating region, decreasing mitigation investments and/or capital investments. As both adaptation and mitigation can be used by a low impact region to compensate a high impact region, having the new option of an adaptation transfer can therefore also decrease mitigation efforts. In the case of climate cooperation, we see that emissions increase slightly. In the case of full cooperation, emissions increase by much more. This is because of an overinvestment of adaptation in adaptation funds receiving regions creating low incentives to mitigate.

This study is subject to several limitations. Firstly the model used here is based on the RICE model and therefore has the same limitations of that model. It does not consider irreversibility and uncertainties and simplifies many relations in the climate and economy. Furthermore, the formulation of adaptation in the model is a flow approach, i.e. adaptation is essentially seen as reactive. A more elaborate stock-and-flow approach may be able to reflect the anticipatory nature of certain types of adaptation measures better. Finally the data used in this study to understand the cost and benefits of adaptation is limited due to the general lack of estimates in this field. More detailed estimates can give us a better understanding of the issues studied here.

\section{Appendix A: AD-RICE Model and parameter calibration}

In this section we describe the AD-RICE model. This model is based on the RICE99 model as described in Nordhaus and Boyer (2000), with a revised damage module, which incorporates adaptation explicitly.

The AD-RICE model consists of $J$ regions, where each region is indexed by $j=1,2, \ldots J$.

Furthermore, there is a planning period indexed by $t=1,2, \ldots T$. Each time step is 10 years starting at 1995 . The social welfare function is defined as;

$$
S W F=\sum_{j=1}^{J} v_{j} \cdot W_{j} .
$$

Where $W_{j}$ is the welfare over the planning period for each region $j$. The region specific weights are given by $v_{j}$. Thus the social welfare is given by the sum of the weighted total utility of all regions.

Next we define the welfare for each region $\mathrm{j}$, which is the utility summed and discounted over all periods;

$$
W_{j}=\sum_{t=0}^{T} U_{j, t} \cdot R_{t},
$$

$R_{t}$ represents the discount factor which is given by;

$$
R_{t}=\prod_{v=o}^{t}[1+\rho(v)]^{-10} .
$$


Furthermore;

$$
\rho(t)=\rho(0) \exp \left(-g_{t}^{\rho}\right)
$$

Next utility in each region for each period is given as:

$$
U_{j, t}=\ln \left(\frac{C_{j, t}}{L_{j, t}}\right) \cdot L_{j, t} .
$$

This is the population weighted natural logarithm of consumption per capita, i.e. total consumption divided by the population; $\ln \left(\frac{C_{j, t}}{L_{j, t}}\right) \cdot L_{j, t}$;

The population is given by;

$$
L_{j, t}=L_{j, 0} \cdot \exp \left(\int_{0}^{t} g_{j, t}^{p o p}\right)
$$

Where;

$$
g_{j, t}^{p o p}=g_{j, 0}^{p o p} \cdot \exp \left(-\partial_{j, t}^{p o p}\right)
$$

Output is a Cobb Douglas function of capital $K_{j, t}$, labour $\left(L_{j, t}\right)$ and energy services from carbon fuels $\left(E S_{j, t}\right)$.The total factor productivity per region per time period $\left(A_{j, t}\right)$ is given by:

$$
Y_{j, t}=\Omega_{j, t} \cdot\left\{A_{j, t} \cdot K_{j, t}^{\gamma} \cdot L_{j, t}^{1-\beta_{j}-\gamma} \cdot E S_{j, t}^{\beta_{j}}-c_{j, t}^{E} \cdot E S_{j, t}\right\}
$$

Where $\Omega_{j, t}$ is the change damage factor and $c_{j, t}^{E}$ are the costs of carbon energy, these depend on the market price $\left(q_{t}\right)$ plus a transport cost markup:

$$
c_{j, t}^{E}=q_{t}+\operatorname{markup}_{j}^{E} .
$$

Carbon services are linked to emissions $\left(E_{j, t}\right)$ :

$$
E S_{j, t}=\varsigma_{j, t} \cdot E_{j, t} .
$$

Furthermore the change in $\varsigma_{j, t}$ is given by; 


$$
\boldsymbol{\zeta}_{j, t}=\boldsymbol{\zeta}_{j, 0} \cdot \exp \left(\int_{0}^{t} g_{j, t}^{Z}\right)
$$

\section{Where}

$$
g_{j, t}^{Z}=g_{j, 0}^{Z} \cdot \exp \left(-\partial_{j, t}^{Z}\right) \text {. }
$$

Total factor productivity $\left(A_{j, t}\right)$ is defined as:

$$
A_{j, t}=A_{j, 0} \cdot \exp \left(\int_{0}^{t} g_{j, t}^{A}\right) .
$$

Where

$$
g_{j, t}^{A}=g_{j, 0}^{A} \cdot \exp \left(-\partial_{j, t}^{A}\right) .
$$

The consumption function is given by:

$$
C_{j, t}=Y_{j, t}-I_{j, t}
$$

Capital accumulation is defined as:

$$
K_{j, t+1}=\left(1-\delta_{k, j}\right) K_{j, t}+I_{j, t} .
$$

Where $\delta_{k, j}$ is the depreciation rate and $I_{j, t}$ the investments in capital. Furthermore it is assumed that capital is immobile between regions.

The first period capital is given:

$$
K_{j, 0}=K_{j}^{*}
$$

Global industrial emissions are the sum of regional industrial emissions:

$$
E_{t}=\sum_{j=1}^{J} E_{j, t}
$$

Total global emissions are the sum of industrial emissions and land-use carbon emissions:

$$
E T_{t}=\sum_{j=1}^{J}\left(E_{j, t}+L U_{j, t}\right) .
$$

Where 
$L U_{j, t}=L U_{j, 0} \cdot\left(1-\delta_{l}\right)^{t}$.

Cumulative emissions are given as:

$$
\operatorname{CumC}_{t+1}=\operatorname{CumC}_{t}+E_{t} \text {. }
$$

The market price of carbon energy depends on the cumulative industrial emissions:

$$
q_{t}=\xi_{1}+\xi_{2} \cdot\left[\operatorname{CumC}_{t} / \operatorname{CumC}^{*}\right]^{\xi_{3}} .
$$

Initial atmospheric concentrations are given:

$$
M_{A T, 0}=M_{A T}^{*} .
$$

Atmospheric carbon concentrations depend on previous concentrations in the atmosphere and upper oceans and on total emissions:

$$
M_{A T, t}=E T_{t-1}+\phi_{11} M_{A T, t-1}+\phi_{21} M_{U P, t-1} .
$$

Carbon concentrations in the upper oceans depend on previous concentrations in the atmosphere, upper oceans and lower oceans;

$$
M_{U P, t}=\phi_{22} M_{U P, t-1}+\phi_{12} M_{A T, t-1}+\phi_{32} M_{L O, t-1} .
$$

Initial carbon concentration in the upper oceans is given:

$$
M_{U P, 0}=M_{U P}^{*} .
$$

Carbon concentrations in the lower oceans depend on previous concentrations in the upper oceans and lower oceans;

$$
M_{L O, t}=\phi_{33} M_{L O, t-1}+\phi_{23} M_{U P, t-1} .
$$

Initial carbon concentration in the lower oceans is given: 


$$
M_{L O, 0}=M_{L O}^{*}
$$

Radiative forcing $\left(F_{t}\right)$ is a function of the ratio of atmospheric concentrations to preindustrial atmospheric concentrations of carbon $\left(\left[M_{A T} / M_{A T}^{P I}\right]\right)$ plus exogenous radiative forcing growth $\left(O_{t}\right)$.

$$
F_{t}=\eta \cdot\left\{\log \left[M_{A T} / M_{A T}^{P I}\right] / \log (2)\right\}+O_{t}
$$

Furthermore;

$$
\begin{aligned}
O_{t} & =-0.1965+0.13465 \cdot t & & t<11 \\
& =1.15 & & t>10
\end{aligned}
$$

Temperature change compared to pre-industrial level is given as:

$$
T_{t}=T_{t-1}+\sigma_{1} \cdot\left\{F_{t}-\lambda \cdot T_{t-1}-\sigma_{2} \cdot\left[T_{t-1}-T_{L O, t-1}\right]\right\}
$$

Where $T_{L O, t}$ is the lower ocean temperature.

Initial temperature change is given:

$$
T_{0}=T^{*}
$$

Lower ocean temperature depends on previous period temperature in the lower ocean and atmosphere.

$$
T_{L O, t}=T_{L O, t-1}+\left[T_{t-1}-T_{L O, t-1}\right]
$$

Initial temperature change is given:

$$
T_{L O, 0}=T_{L O}^{*}
$$

The climate change damage factor is given as:

$$
\Omega_{j, t}=\frac{1}{1+D_{j, t}}
$$

$D_{j, t}$ is the damage due to climate change and is given as a function of temperature change in the atmosphere.

We define gross damages of climate change as a percentage of output $\left(G D_{j, t}\right)$ as a function of the temperature change as shown in the following equation;

$$
G D_{j, t}=\beta_{1, j} T_{t}+\beta_{2, j} T_{t}^{\beta_{3, j}}
$$


The residual damages of climate change are the damages after adaptation to climate change has taken place. Regions can change economic, social and cultural structures to decrease the damages or increase benefits of climate change in their region, that is adapt. Residual damages as a percentage of output $\left(R D_{j, t}\right)$ are a function of adaptation $\left(P_{j, t}\right.$ and $\left.P R_{j, t}\right)$ and gross damages $\left(G D_{j, t}\right)$, where $P_{j, t}\left(0 \leq P_{j, t} \geq 1\right)$ represents the fraction by which gross damages are reduced and $P R_{j, t}\left(0 \leq P R_{j, t} \geq 1\right)$ represents the fraction by which gross benefits are increased, this is given in equation A.38.

$$
\begin{array}{ll}
R D_{j, t}=\left(1-P_{j, t}\right) \cdot G D_{j, t} & G D_{j, t}>0 \\
R D_{j, t}=\left(1-P R_{j, t}\right) \cdot G D_{j, t} & G D_{j, t}<0
\end{array}
$$

Adaptation comes at a cost though; the adaptation costs as a function of output $\left(P C_{j, t}\right)$ are the costs of adaptation. The cost function is a function of $P_{j, t}$ and $P R_{j, t}$. Where the coefficients are $\gamma_{1, j}$ and $\gamma_{2, j}$ are different across regions, furthermore $\gamma_{1, j}>0$ and $\gamma_{2, j}>1$ :

$$
P C_{j, t}=\gamma_{1, j} \cdot\left(P_{j, t}+P R_{j, t}\right)^{\gamma_{2, j}}
$$

Finally:

$$
D_{j, t}=R D_{j, t}+P C_{j, t}
$$

The residual damages together with the adaptation costs form the net climate change damages defined as $D_{j, t}$ in the original RICE model. Furthermore the residual damages, the adaptation costs and mitigation costs together represent the total costs of climate change $\left(\left(R D_{j, t}+P C_{j, t}+M C_{j, t}\right) \cdot Y_{j, t}\right)$.

In the model the regions can choose different levels of consumption, capital investment, mitigation and adaptation to fulfil their objectives.

The calibrated parameter values for equations A.37 and A.39 are given in table A1. 
Table A1: Parameter values from AD-RICE in the optimal scenario calibration.

\begin{tabular}{|l|l|l|l|l|l|}
\hline & \multicolumn{1}{|c|}{$\beta 1$} & \multicolumn{1}{|c|}{$\beta 2$} & \multicolumn{1}{c|}{$\beta 3$} & \multicolumn{1}{r|}{$\gamma 1$} & \multicolumn{1}{r|}{$\gamma 2$} \\
\hline JAPAN & -0.0028 & 0.0012 & 2.65 & 0.031 & 3.26 \\
\hline USA & -0.0010 & 0.0004 & 4.06 & 0.016 & 10.21 \\
\hline EUROPE & -0.0002 & 0.0046 & 2.29 & 0.341 & 4.24 \\
\hline HIO & - & 0.0070 & 1.53 & 0.315 & 5.19 \\
\hline MI & - & 0.00587 & 1.49 & 0.216 & 3.97 \\
\hline LMI & - & 0.00571 & 1.85 & 0.332 & 5.06 \\
\hline LI & - & 0.01091 & 1.55 & 0.502 & 5.18 \\
\hline CHINA & -0.0022 & 0.00064 & 2.97 & 0.0225 & 6.29 \\
\hline INDIA & - & 0.01512 & 1.70 & 0.783 & 5.28 \\
\hline AFRICA & - & 0.02152 & 1.21 & 0.751 & 5.12 \\
\hline
\end{tabular}

\section{Appendix B: Optimal mitigation levels}

In the following we derive the optimal levels of mitigation for the different model specifications as described in Section 3.

\section{B.1. Application to the model with implicit adaptation}

The simplest specification, with implicit adaptation can be solved using the Pontryagin maximum principle (Pontryagin 1962) for a dynamic optimisation problem with 1 control variable, mitigation $(\mu)$, and a state variable, total cumulative emissions $(M)$. Although our problem includes multiple regions, we omit regional subscripts here as we derive the Nash solution. In this case each region optimises only its own consumption given the level of emissions by the other players.

In the dynamic solution each region maximizes:

$$
\sum_{t=1}^{T} \rho \cdot V\left(\mu_{t}, M_{t}\right)+\rho^{T+1} F\left(M_{T+1}\right) .
$$

Subject to the following equation of motion and start value of the state variable.

$$
M_{t+1}-M_{t}=f\left(\mu_{t}\right)
$$


Using the Pontryagin maximum principle, the corresponding discrete time current value Hamiltonian is:

$$
H\left(\mu_{t}, M_{t}, \lambda_{t+1}\right)=V(.)+\rho_{t} \cdot \lambda_{t+1} f(.)
$$

The corresponding first order conditions of the maximum principle are as follows:

$$
\begin{aligned}
& M_{t+1}=\frac{\partial H(.)}{\partial\left(\rho_{t} \cdot \lambda_{t+1}\right)}, \quad M_{1}=\bar{M} \\
& \rho_{t} \cdot \lambda_{t+1}-\lambda_{t}=-\frac{\partial H(.)}{\partial M_{t}} \\
& \frac{\partial H(.)}{\partial \mu_{t}}=0
\end{aligned}
$$

The value function is simply the instantaneous utility function, which in our simple model diminishes to consumption as the residual of income after climate costs (damages and mitigation costs):

$$
V\left(\mu_{t}, M_{t}\right)=Y_{t}-\varphi \cdot M_{t} \cdot Y_{t}-\theta_{1, t} \cdot \mu_{t}^{\theta_{2, t}} \cdot Y_{t}
$$

Furthermore the equation of motion is given by the build-up of the stock of $\mathrm{CO} 2$ over time, which depends on emissions after mitigation:

$$
f\left(\mu_{t}\right)=\Omega \cdot Y_{t} \cdot\left(1-\mu_{t}\right)+E x_{t} .
$$

Where Ex is are exogenous emissions (emissions from other players).

We also impose

$$
\lambda_{T+1}=\frac{\partial F(.)}{\partial M_{T+1}}=0,
$$

i.e. the impact of $\mathrm{CO} 2$ stocks beyond the model horizon are not taken into account (which is not a major problem if the model horizon is sufficiently long).

The first order conditions then result in: 


$$
\begin{aligned}
& M_{t+1}=M_{t}+\Omega \cdot Y_{t}\left(1-\mu_{t}\right)+E x_{t} \\
& \rho_{t} \cdot \lambda_{t+1}-\lambda_{t}=\varphi \cdot Y_{t} \\
& -\theta_{2, t} \cdot \theta_{1, t} \cdot \mu_{t}^{\theta_{2, t}-1} \cdot Y_{t}+\rho_{t} \cdot \lambda_{t+1} \cdot(-1) \cdot \Omega \cdot Y_{t}=0
\end{aligned}
$$

Rewriting (A.53) we find the optimal level of mitigation:

$$
\mu_{t}^{*}=\left(\frac{-\rho_{t} \cdot \lambda_{t+1}^{*} \cdot \Omega}{\theta_{2, t} \cdot \theta_{1, t}}\right)^{\frac{1}{\theta_{2, t}-1}}
$$

where the asterix refers to the optimal levels.

Condition (A.10) states that $\lambda_{T+1}=0$, and thus by solving recursively, we can express $\lambda_{t} *$ as follows:

$$
\lambda_{t}^{*}=\sum_{s=t}^{T}\left(-\varphi \cdot Y_{s} \cdot \rho_{s}\right) .
$$

Substituting (A.55) in (A.54) yields;

$$
\mu_{t}^{*}=\left(\frac{\sum_{s=t+1}^{T}\left(\varphi \cdot Y_{s} \cdot \rho_{s}\right) \cdot \Omega}{\theta_{2, t} \cdot \theta_{1, t}}\right)^{\frac{1}{\theta_{2, t}-1}}
$$

\section{B.2. Application to the model with explicit adaptation}

Here we present the optimal level of mitigation and adaptation for the case where we include an explicit adaptation variable. ${ }^{16}$

The value function now includes adaptation efforts, $P$, as an additional control variable and adaptation costs as a competing claim to income;

$$
V\left(\mu_{t}, P_{t}, M_{t}\right)=Y_{t}-\omega_{1} \cdot M_{t} \cdot Y_{t} \cdot\left(1-P_{t}\right)-\theta_{1, t} \cdot \mu_{t}^{\theta_{2, t}} \cdot Y_{t}-\gamma_{1} \cdot P_{t}^{\gamma_{2}} \cdot Y_{t}
$$

The equation of motion is still given by equation A.49:

$f\left(\mu_{t}\right)=\Omega \cdot Y_{t} \cdot\left(1-\mu_{t}\right)+E x_{t}$.

${ }^{16}$ Again we omit regional subscripts as we are calculating the Nash solution. 
The first order conditions of the maximum principle (A.51) and (A.53) and condition (A.50) are unchanged, A.52 changes into A.58;

$$
\rho_{t} \cdot \lambda_{t+1}-\lambda_{t}=\omega \cdot Y_{t} \cdot\left(1-P_{t}\right)
$$

And an additional equation governs the optimal level of adaptation:

$$
\frac{\partial H(.)}{\partial P}=0
$$

These conditions result in:

$$
\begin{aligned}
& \rho_{t} \cdot \lambda_{t+1}-\lambda_{t}=\omega \cdot Y_{t} \cdot\left(1-P_{t}\right) \\
& \omega \cdot M_{t} \cdot Y_{t}-\gamma_{2} \cdot \gamma_{1} \cdot P_{t}^{\gamma_{2}-1} \cdot Y_{t}=0
\end{aligned}
$$

We can rewrite (A.61), finding the optimal level of adaptation:

$$
P_{t}^{*}=\left(\frac{\omega \cdot M_{t}}{\gamma_{2} \cdot \gamma_{1}}\right)^{\frac{1}{\gamma_{2}-1}}
$$

The corresponding optimal level of adaptation costs (PC) is given as:

$$
\operatorname{PC}\left(P_{t}^{*}\right)=\gamma_{1} \cdot Y_{t} \cdot\left[\left(\frac{\omega \cdot M_{t}}{\gamma_{2} \cdot \gamma_{1}}\right)^{\frac{1}{\gamma_{2}-1}}\right]^{\gamma_{2}}=\gamma_{1} \cdot Y_{t} \cdot\left(\frac{\omega \cdot M_{t}}{\gamma_{2} \cdot \gamma_{1}}\right)^{\frac{\gamma_{2}}{\gamma_{2}-1}}
$$

The optimal level of mitigation is still given by equation A.54:

$$
\mu_{t}^{*}=\left(\frac{-\rho_{t} \cdot \lambda_{t+1}^{*} \cdot \Omega}{\theta_{2, t} \cdot \theta_{1, t}}\right)^{\frac{1}{\theta_{2, t}-1}}
$$

Using $\lambda_{T+1}=0$ and solving recursively, we can express $\lambda_{t}$ as follows:

$$
\lambda_{t}^{*}=\sum_{s=t}^{T}\left(-\omega \cdot Y_{s} \cdot\left(1-P_{s}^{*}\right) \cdot \rho_{s}\right)
$$

Substituting (A.64) in (A.54) yields the optimal level of mitigation with explicit adaptation; 


$$
\mu_{t}^{*}=\left(\frac{\sum_{s=t+1}^{T}\left(\omega \cdot Y_{s} \cdot\left(1-P_{s}^{*}\right) \cdot \rho_{s}\right) \cdot \Omega}{\theta_{2, t} \cdot \theta_{1, t}}\right)^{\frac{1}{\theta_{2, t}-1}}
$$

\section{Appendix C: Cooperative solutions with transfers}

When introducing transfers we no longer use the level of adaptation as a decision variable but use the level of adaptation costs instead. Since these two variables are linked directly this will not change the solution but is needed to ensure that transfers are spent on adaptation.

In its most simple form the problem can be solved for 2 regions ( $D$ and $H$ ) using the Pontryagin maximum principle (Pontryagin 1962) for a dynamic optimisation problem with 5 control variable, mitigation for each region $\left(\mu_{D}, \mu_{H}\right)$, adaptation costs for each region $\left(P C_{D}, P C_{H}\right)$ and an adaptation transfers from $D$ to $H(T A)$ and a state variable, total cumulative emissions ( $M$ ).

In the dynamic solution the regions maximizes:

$$
\sum_{t=1}^{T} \rho_{t} \cdot V\left(\mu_{D, t}, \mu_{H, t}, P C_{D, t}, P C_{H, t}, T A_{t}, M_{t}\right)+\rho_{T+1} F\left(M_{T+1}\right) .
$$

Subject to the following equation of motion and start value of the state variable as in Appendix B: (A.42) and (A.43).

$$
\begin{aligned}
& M_{t+1}-M_{t}=f\left(\mu_{D, t}, \mu_{H, t}\right) \\
& M_{1}=\bar{M}
\end{aligned}
$$

Using the Pontryagin maximum principle the corresponding discrete time current value Hamiltonian is:

$$
H\left(\mu_{D, t}, \mu_{H, t}, P C_{D, t}, P C_{H, t}, T A, M_{t}, \lambda_{t+1}\right)=V(.)+\rho_{t} \cdot \lambda_{t+1} f(.)
$$

The corresponding first order conditions of the maximum principle are as follows :

$$
M_{t+1}=\frac{\partial H(.)}{\partial\left(\rho_{t} \cdot \lambda_{t+1}\right)}, \quad M_{1}=\bar{M}
$$


as in (A.45).

$\rho_{t} \cdot \lambda_{t+1}-\lambda_{t}=-\frac{\partial H(.)}{\partial M_{t}}$

as in (A.46).

$\frac{\partial H(.)}{\partial \mu_{D, t}}=0$

$\frac{\partial H(.)}{\partial \mu_{H, t}}=0$

$\frac{\partial H(.)}{\partial P C_{D, t}}=0$

$\frac{\partial H(.)}{\partial P C_{H, t}}=0$

$$
\frac{\partial H(.)}{\partial T A_{t}}=0
$$

$V\left(\mu_{D, t}, \mu_{H, t}, P C_{D, t}, P C_{H, t}, T A_{t}, M_{t}\right)=$

$v_{D} \cdot \log \left(Y_{D, t}-\omega_{D} \cdot M_{t} \cdot Y_{D, t} \cdot\left[1-\left(\frac{P C_{D, t}}{\gamma_{1, D} \cdot Y_{D, t}}\right)^{\frac{1}{\gamma_{2, D}}}\right]-\theta_{1, D, t} \cdot \mu_{D, t}^{\theta_{2, D, t}} \cdot Y_{D, t}-P C_{D, t}-T A_{t}\right)$

$+v_{H} \cdot \log \left(Y_{H, t}-\omega_{H} \cdot M_{t} \cdot Y_{H, t} \cdot\left[1-\left(\frac{P C_{H, t}+T A_{t}}{\gamma_{1, H} \cdot Y_{H, t}}\right)^{\frac{1}{\gamma_{2, P}}}\right]-\theta_{1, H, t} \cdot \mu_{H, t}^{\theta_{2, H, t}} \cdot Y_{H, t}-P C_{H, t}\right)$

$f\left(\mu_{D, t}, \mu_{H, t}\right)=\Omega_{D} \cdot Y_{D, t} \cdot\left(1-\mu_{D, t}\right)+\Omega_{H} \cdot Y_{H, t} \cdot\left(1-\mu_{H, t}\right)$.

We also impose as in (A.50):

$\lambda_{T+1}=\frac{\partial F(.)}{\partial M_{T+1}}=0$

i.e. the impact of $\mathrm{CO} 2$ stocks beyond the model horizon are not taken into account (which is not a major problem if the model horizon is sufficiently long). 
The first order condition (A.45) then result in:

$$
M_{t+1}=M_{t}+\Omega_{D} \cdot Y_{D, t} \cdot\left(1-\mu_{D, t}\right)+\Omega_{H} \cdot Y_{H, t} \cdot\left(1-\mu_{H, t}\right)
$$

The first order condition (A.46) then result in:

$$
\begin{aligned}
& \rho_{t} \cdot \lambda_{t+1}-\lambda_{t}= \\
& \frac{1}{Y_{D, t}-\omega_{D} \cdot M_{t} \cdot Y_{D, t} \cdot\left[1-\left(\frac{P C_{D, t}}{\gamma_{1, D} \cdot Y_{D, t}}\right)^{\frac{1}{\gamma_{2, D}}}\right]-\theta_{1, D, t} \cdot \mu_{D, t}^{\theta_{2, D, t}} \cdot Y_{D, t}-P C_{D, t}-T A_{t}} \\
& \cdot \omega_{D} \cdot M_{t} \cdot Y_{D, t} \cdot\left[1-\left(\frac{P C_{D, t}}{\gamma_{1, D} \cdot Y_{D, t}}\right)^{\frac{1}{\gamma_{2, D}}}\right] \\
& +\frac{1}{Y_{H, t}-\omega_{H} \cdot M_{t} \cdot Y_{H, t} \cdot\left[1-\left(\frac{P C_{H, t}+T A_{t}}{\gamma_{1, H} \cdot Y_{H, t}}\right)^{\frac{1}{\gamma_{2, H}}}\right]-\theta_{1, H, t} \cdot \mu_{H, t}^{\theta_{2, H, t}} \cdot Y_{H, t}-P C_{H, t}} \\
& \omega_{H} \cdot Y_{H, t} \cdot\left[1-\left(\frac{P C_{H, t}+T A_{t}}{\gamma_{1, H} \cdot Y_{H, t}}\right)^{\frac{1}{\gamma H}}\right] \\
& =\frac{1}{C_{D, t}} \cdot \omega_{D} \cdot M_{t} \cdot Y_{D, t} \cdot\left[1-\left(\frac{P C_{D, t}}{\gamma_{1, D} \cdot Y_{D, t}}\right)^{\frac{1}{\gamma_{2, D}}}\right] \\
& +\frac{1}{C_{H, t}} \cdot \omega_{H} \cdot Y_{H, t} \cdot\left[1-\left(\frac{P C_{H, t}+T A_{t}}{\gamma_{1, H} \cdot Y_{H, t}}\right)^{\frac{1}{\gamma_{2, H}}}\right]
\end{aligned}
$$

The first order condition (A.68) then result in:

$$
\frac{1}{C_{D, t}} \cdot-\theta_{2, D, t} \cdot \theta_{1, D, t} \cdot \mu_{D, t}^{\theta_{2, D, t}-1} \cdot Y_{D, t}+\rho_{t} \cdot \lambda_{t+1} \cdot(-1) \cdot \Omega_{D} \cdot Y_{D, t}=0
$$

The first order condition (A.60) then result in:

$$
\frac{1}{C_{R, t}} \cdot-\theta_{2, H, t} \cdot \theta_{1, H, t} \cdot \mu_{H, t}^{\theta_{2, H, t}-1} \cdot Y_{H, t}+\rho_{t} \cdot \lambda_{t+1} \cdot(-1) \cdot \Omega_{H} \cdot Y_{H, t}=0
$$

The first order condition (A.70) then result in: 


$$
\frac{\omega_{D} \cdot M_{t}}{\gamma_{1, D} \cdot \gamma_{2, D}} \cdot\left(\frac{P C_{D, t}}{\gamma_{1, D} \cdot Y_{D, t}}\right)^{\frac{1}{\gamma_{2, D}}-1}=1
$$

The first order condition (A.71) then result in:

$$
\frac{\omega_{H} \cdot M_{t}}{\gamma_{1, H} \cdot \gamma_{2, H}} \cdot\left(\frac{P C_{H, t}+T A_{t}}{\gamma_{1, H} \cdot Y_{H, t}}\right)^{\frac{1}{\gamma_{2, H}-1}}=1
$$

(A.80)

The first order condition (A.72) then result in:

$$
\frac{1}{C_{H, t}} \cdot v_{H} \cdot \frac{\omega_{H} \cdot M_{t}}{\gamma_{1, H} \cdot \gamma_{2, H}} \cdot\left(\frac{P C_{H, t}+T A_{t}}{\gamma_{1, H} \cdot Y_{H, t}}\right)^{\frac{1}{\gamma_{2, H}}-1}=\frac{1}{C_{D, t}} \cdot v_{D}
$$

The corresponding optimal level of $P C_{H, t}$ is given by rewriting (A.80):

$$
P C_{H, t}=\gamma_{1, H} \cdot Y_{H, t} \cdot\left(\frac{\gamma_{1, H} \cdot \gamma_{2, H}}{\omega_{H} \cdot M_{t}}\right)^{\frac{\gamma_{2, H}}{\gamma_{2, H}-1}}-T A_{t}
$$

The corresponding optimal level of $T A_{t}$ is given by rewriting (A.82):

$$
T A_{t}=\gamma_{1, H} \cdot Y_{H, t} \cdot\left(\frac{\frac{1}{C_{D, t}} \cdot v_{D}}{\frac{1}{C_{H, t}} \cdot v_{H}} \cdot \frac{\gamma_{1, H} \cdot \gamma_{2, H}}{\omega_{H} \cdot M_{t}}\right)^{\frac{\gamma_{2, H}}{\gamma_{2, H}-1}}-P C_{H, t}
$$

\section{Appendix D. Proofs}

Proof of Proposition 1. To proof that making adaptation explicit in the optimum will have no effect on the optimal levels of mitigation; we need to show that the optimal level of mitigation can be expressed in only terms of mitigation and exogenous parameters.

When $P_{j, t}$ is set at its optimal level it can be expressed as;

$$
P_{j, t}^{*}=\left(\frac{\omega_{j} \cdot M_{t}}{\gamma_{2, j} \cdot \gamma_{1, j}}\right)^{\frac{1}{\gamma_{2, j}-1}} .
$$


Since we assume that $M_{1}=\bar{M}$ ( A.43) and $M_{t+1}=M_{t}+\Omega_{j} \cdot Y_{j, t}\left(1-\mu_{j, t}\right)+E x_{t}$ (A.51) and $E x_{t}$ is given, we can find the optimal mitigation path through forward induction. Thus $M_{t}$ only depends on mitigation $(\mu)$ as follows:

$M_{t}=\bar{M}+\sum_{t=1}^{t} \Omega \cdot Y_{t}\left(1-\mu_{t}\right)+E x_{t}$

and therefore mitigation can be expressed in exogenous parameters and mitigation as follows (substituting in ):

$\left.\mu_{t}^{*}=\left(\frac{1}{\theta_{2, t} \cdot \theta_{1, t}} \cdot \sum_{s=t+1}^{T}\left(\omega \cdot Y_{s} \cdot \rho_{s} \cdot\left(1-\left(\frac{\omega_{j} \cdot\left(\bar{M}+\sum_{t=1}^{t} \Omega \cdot Y_{t}\left(1-\mu_{t}\right)+E x_{t}\right)}{\gamma_{2, j} \cdot \gamma_{1, j}}\right)\right) \cdot \Omega\right)^{\frac{1}{\gamma_{2, j}-1}}\right)\right)$

Proof of Proposition 2a. To proof that foreign adaptation funding will fully crowd out domestic adaptation funding, we will show that when host adaptation expenditures are set at their optimal levels, the derivative of PC to TA is -1 .

When introducing an adaptation transfer to region $\mathrm{P}$, the optimal level of adaptation expenditures in region when transfers are present $\left(P C_{F}\right)$ are as follows (see equation A.82):

$P C_{F}\left(P_{H, t}^{*}\right)=\gamma_{1, H} \cdot Y_{H, t} \cdot\left(\frac{\omega_{H} \cdot M_{t}}{\gamma_{1, H} \cdot \gamma_{2, H}}\right)^{\frac{\gamma_{2, H}}{\gamma_{2, H}-1}}-T A_{t}$.

$\frac{\partial P C_{F}\left(P_{H, t}^{*}\right)}{\partial T A_{t}}=-1$

Thus for every additional dollar of foreign funding, domestic adaptation expenditure will decrease by one dollar.

Proof of Proposition 2b. To proof that adaptation will not be crowded out when $P C_{H, t}+T A_{t}<P C_{F}\left(P^{*}\right)_{H, t}$ we have to show that the marginal benefits of adaptation will exceed or equal the marginal costs at that point, i.e. given that level of adaptation transfers. We will prove that for $\frac{\partial C_{H}}{\partial P C_{H, t}} \leq \frac{\partial R D_{H}}{\partial P C_{H, t}}$ to hold $P C_{H, t}+T A_{t}<P C_{F}\left(P^{*}\right)_{H, t}$ must hold. To prove this we assume the contrary;

$P C_{H, t}+T A_{t} \geq P C\left(P^{*}\right)_{H, t}$.

We find applying (A.63) that when

$P C_{H, t}+T A_{t}=P C_{F}\left(P_{H, t}^{*}\right)=\gamma_{1, H} \cdot Y_{H, t} \cdot\left(\frac{\omega_{H} \cdot M_{t}}{\gamma_{1, H} \cdot \gamma_{2, H}}\right)^{\frac{\gamma_{2, H}}{\gamma_{2, H}-1}}$, 
$\rightarrow \frac{\omega_{H} \cdot M_{t}}{\gamma_{1, H} \cdot \gamma_{2, H}} \cdot\left(\frac{P C_{H, t}+T A_{t}}{\gamma_{1, H} \cdot Y_{H, t}}\right)^{\frac{1}{\gamma_{2, H}}-1}=\frac{\omega_{H} \cdot M_{t}}{\gamma_{1, H} \cdot \gamma_{2, H}} \cdot\left(\frac{\left.\gamma_{1, H} \cdot Y_{H, t} \cdot\left(\frac{\omega_{H} \cdot M_{t}}{\gamma_{1, H} \cdot \gamma_{2, H}}\right)^{\frac{\gamma_{2, H}}{\gamma_{2, H}-1}}\right)^{\frac{1}{\gamma_{2, H}}-1}}{\gamma_{1, H} \cdot Y_{H, t}}=1\right.$

Furthermore when $P C_{H, t}+T A_{t}>P C\left(P^{*}\right)_{H, t}$

$\rightarrow 1>\frac{\omega_{H} \cdot M_{t}}{\gamma_{1, H} \cdot \gamma_{2, H}} \cdot\left(\frac{P C_{H, t}+T A_{t}}{\gamma_{1, H} \cdot Y_{H, t}}\right)^{\frac{1}{\gamma_{2, H}}-1}$

$\frac{\partial C_{H}}{\partial P C_{t}}>\frac{\partial R D_{H}}{\partial P C_{t}}$

Which is a contradiction, which proves that $P C_{H, t}+T A_{t}<P C_{F}\left(P^{*}\right)_{H, t}$ must hold for $\frac{\partial C_{H}}{\partial P C_{H, t}} \leq \frac{\partial R D_{H}}{\partial P C_{H, t}}$ to hold.

Proof of Proposition 3a. To proof that adaptation transfers will not take place in the competitive Nash equilibrium, we show that the optimal transfer is zero when optimising the SWF function using Negishi weights.

$T A_{t}^{*}=\gamma_{1, H} \cdot Y_{H, t} \cdot\left(\frac{v_{D} / C_{D, t}}{v_{H} / C_{H, t}} \cdot \frac{\omega_{H} \cdot M_{t}}{\gamma_{1, H} \cdot \gamma_{2, H}}\right)^{\frac{\gamma_{2, H}}{\gamma_{2, H}-1}}-P C_{H, t}$,

where $v_{1}, v_{2}$ are the welfare weights. These are equal to the inverse of the marginal utility of consumption in the competitive equilibrium (Negishi 1960), giving

$$
v_{j, t}=\frac{1}{\frac{\partial U_{j}}{\partial C_{j, t}}}=\frac{1}{\frac{1}{C_{j, t}}}=C_{j, t} .
$$

This results in

$$
\begin{aligned}
T A_{t}^{*} & =\gamma_{1, H} \cdot Y_{H, t} \cdot\left(\frac{C_{D} / C_{D, t}}{C_{H} / C_{H, t}} \cdot \frac{\omega_{H} \cdot M_{t}}{\gamma_{1, H} \cdot \gamma_{2, H}}\right)^{\frac{\gamma_{2, H}}{\gamma_{2, H}-1}}-P C_{H, t} \\
& =\gamma_{1, H} \cdot Y_{H, t} \cdot\left(\frac{\omega_{H} \cdot M_{t}}{\gamma_{1, H} \cdot \gamma_{2, H}}\right)^{\frac{\gamma_{2, H}}{\gamma_{2, H}-1}}-P C_{H, t}
\end{aligned}
$$

When adaptation expenditures are set at the internally optimal levels in region $\mathrm{P}, P C_{H, t}$, will be set at the level as in (A.63): 
$P C_{H, t}=\gamma_{1, H} \cdot Y_{H, t} \cdot\left(\frac{\omega_{H} \cdot M_{t}}{\gamma_{1, H} \cdot \gamma_{2, H}}\right)^{\frac{\gamma_{2, H}}{\gamma_{2, H}-1}}$

Resulting in

$T A_{t}^{*}=\gamma_{1, H} \cdot Y_{H, t} \cdot\left(\frac{\omega_{H} \cdot M_{t}}{\gamma_{1, H} \cdot \gamma_{2, H}}\right)^{\frac{\gamma_{2, H}}{\gamma_{2, H}-1}}-\gamma_{1, H} \cdot Y_{H, t} \cdot\left(\frac{\omega_{H} \cdot M_{t}}{\gamma_{1, H} \cdot \gamma_{2, H}}\right)^{\frac{\gamma_{2, H}}{\gamma_{2, H}-1}}=0$

Proof of Proposition 3b. We prove that adaptation transfers will be positive in the case of climate cooperation when there are differences in impacts across regions and transfers will run from low impact to high impact regions. We show that using the climate cooperation welfare weight, transfers indeed will take place when there are differences in impacts and run from low to high impact regions.

The SWF is now maximised using the welfare weights in the case that there are no damages from climate change. The logic here is that countries should receive the same weight as they would have in the competitive equilibrium when climate change did not occur. The welfare weights equal the inverse of the marginal utility of consumption when there are no damages from climate change. $v_{j, t}=Y_{j, t}$. This results in an optimal adaptation transfer given by:

$T A_{t}^{*}=\gamma_{1, H} \cdot Y_{H, t} \cdot\left(\frac{Y_{D} / C_{D, t}}{Y_{H} / C_{H, t}} \cdot \frac{\omega_{H} \cdot M_{t}}{\gamma_{1, H} \cdot \gamma_{2, H}}\right)^{\frac{\gamma_{2, H}}{\gamma_{2, H}-1}}-P C_{H, t}$

When adaptation expenditures are set at the internal optimal levels in region $\mathrm{H}, P C_{H, t}$ will be set at the level as given in Proposition 2a (A.63):

$P C_{H, t}=\gamma_{1, H} \cdot Y_{H, t} \cdot\left(\frac{\omega_{H} \cdot M_{t}}{\gamma_{1, H} \cdot \gamma_{2, H}}\right)^{\frac{\gamma_{2, H}}{\gamma_{2, H}-1}}$.

Transfers will thus take place from region $\mathrm{D}$ to $\mathrm{H}$ only in the case where $\frac{Y_{D, t} / C_{D, t}}{Y_{H, t} / C_{H, t}}<1$, as $\frac{\gamma_{2,2}}{1-\gamma_{2,2}}<0$. This is only the case if $\frac{Y_{D, t}}{C_{D, t}}<\frac{Y_{H, t}}{C_{H, t}}$. This entails that the negative effects of climate change (the damages) are lower in region $\mathrm{R}$.

Proof of Proposition 3c. We prove that adaptation transfers will take place when global utility is maximised when there are differences between income consumption levels across regions and that transfers will run from high income regions to low income regions. To do this we show that when using equal welfare weights this is the case.

When global utility is maximised the welfare weights take the value of 1 for all regions. Resulting in an optimal transfer of: 
$T A_{t}^{*}=\gamma_{1, H} \cdot Y_{H, t} \cdot\left(\frac{1 / C_{D, t}}{1 / C_{H, t}} \cdot \frac{\omega_{H} \cdot M_{t}}{\gamma_{1, H} \cdot \gamma_{2, H}}\right)^{\frac{\gamma_{2, H}}{\gamma_{2, H}-1}}-P C_{H, t}$

When adaptation expenditures are set at the internally optimal levels in region $\mathrm{H}, P C_{P, t}$ will be set at the level as given in (A.63):

$P C_{H, t}=\gamma_{1, H} \cdot Y_{H, t} \cdot\left(\frac{\omega_{H} \cdot M_{t}}{\gamma_{1, H} \cdot \gamma_{2, H}}\right)^{\frac{\gamma_{2, H}}{\gamma_{2, H}-1}}$.

Transfers will thus take place from region $\mathrm{D}$ to region $\mathrm{H}$ only in the case where $\frac{C_{D, t}}{C_{H, t}}>1$, i.e. when consumption is higher in region $\mathrm{D}$.

\section{References}

Barrett, S., 2001. International Cooperation for Sale. European Economic Review 45, 18351850.

Bosetti, V., Carraro, C. , de Cian, E., Duval, R., Massetti, E., Tavoni, M., 2009. The Incentives to Participate in and the Stability of International Climate Coalitions: a Game-theoretic Analysis using the WITCH model. OECD Economics Department Working Paper 702, Paris.

Bouwer, L., Aerts, J., 2006. Financing Climate Change Adaptation. Disasters Vol 30, No 1, 49-63.

Bruin, de K.C., Dellink, R.B., Tol, R.S.J., 2009a. AD-DICE: an implementation of adaptation in the DICE model. Climatic Change 95, 63-81.

Bruin, de K.C., Dellink, R.B., Agrawala, S., 2009b. Economic Aspects of Adaptation to Climate Change: Integrated Assessment Modelling of Adaptation Costs and Benefits. OECD Environment Working Papers 6, OECD Publishing, Paris.

Bruin, de K.C., Dellink, R.B., 2009. How harmful are adaptation restrictions? FEEM Working Paper 58, FEEM, Milan.

Burton, I., Huq, S., Lim, B., Pilifosova, O., and Schipper, E. L., 2002. From Impacts Assessment to Adaptation Priorities: the Shaping of Adaptation Policies, Climate Policy 2, 145-159.

Carraro, C., Eyckmans, J., Finus, M., 2006. Optimal Transfers and Participation Decisions in International Environmental Agreements. Review of International Organizations 1, 379-396.

Chander, P., Tulkens, H., 1997. The Core of an Economy with Multilateral Environmental Externalities. International Journal of Game Theory 26, 379-401. 
Dellink, R.B., de Bruin, K.C., de Ruiter, M., forthcoming. Fitting the original linear climate model to the revised DICE model: a regression analysis. Institute for Environmental Studies, VU University Amsterdam.

Dellink, R.B., den Elzen, M., Aiking, H., Bergsma, E., Berkhout, F., Dekker, T., Gupta, J. 2009. Sharing the Burden of Adaptation Financing. Global Environmental Change 19, 411-421.

Drunen, M. van, Bouwer, L., Dellink, R., Gupta, J., Massey, E., Pauw, P., 2009. Financing Adaptation in Developing Countries: Assessing New Mechanisms. WAB report 500102 025, Bilthoven, and IVM report W-09/02, Amsterdam.

Hof, A. F., Bruin, de K.C., Dellink, R.B., den Elzen, M. G.J., Vuuren, van D.P., forthcoming. The Effect of Different Mitigation Strategies on International Financing of Adaptation, Environmental Science \& Policy.

IPCC, 2007. Contribution of Working Group III to the Fourth Assessment Report of the Intergovernmental Panel on Climate Change. Cambridge Univeristy Press, Cambridge.

Jacoby, H.D., et al., 2004. Technology and Technical Change in the MIT EPPA Model. MIT Joint Program on the Science and Policy of Global Change Report Series, \# 111, MIT, Cambridge, MA.

Nagashima, M., Dellink, R.B., Ierland van E.C., Weikard, H.P., 2009. Stability of International Climate Coalitions - a Comparison of Transfer Schemes. Ecological Economics 68, pp. 1476-1487.

Negishi, T., 1960. Welfare Economics and Existence of an Equilibrium for a Competitive Economy, Metroeconomics 12, pp. 92-92.

Nordhaus, W.D., Yang, Z., 2006. Magnitude and Direction of Technological Transfers for Mitigating GHG Emissions. Energy Economics 28, pp.730-741.

Nordhaus, W.D., Boyer, J., 2000. Warming the World: Economic Models of Global Warming. MIT Press, Cambridge, MA.

Paavola, J., Adger, W.N., 2006. Fair Adaptation to Climate Change, Ecological Economics 56 , pp. 594-609.

Pontryagin, L.S., Boltyanskii, V.G., Gamkrelidze, R.V., Mishchenko, E.F., 1962. The Mathematical Theory of Optimal Processes. Fitzmatgiz, Moscow, 1961; English transl., Wiley, New York.

UNFCC, 2007. Bali Action Plan, FCCC/KP/CMP/2007/9, http://unfccc.int/resource/docs/2007/cmp3/eng/09.pdf 


\section{NOTE DI LAVORO DELLA FONDAZIONE ENI ENRICO MATTEI}

\section{Fondazione Eni Enrico Mattei Working Paper Series}

Our Note di Lavoro are available on the Internet at the following addresses:

http://www.feem.it/getpage. aspx?id=73\&sez=Publications\&padre=20\&tab=1

http://papers.ssrn.com/sol3/JELJOUR_Results.cfm?form_name=journalbrowse\&journal_id=266659 http://ideas.repec.org/s/fem/femwpa.html

http://www.econis.eu/LNG=EN/FAM?PPN=505954494

http://ageconsearch.umn.edu/handle/35978

http://www.bepress.com/feem/

\section{NOTE DI LAVORO PUBLISHED IN 2010}

1.2010 Cristina Cattaneo: Migrants' International Transfers and Educational Expenditure: Empirical Evidence from Albania

2.2010 Fabio Antoniou, Panos Hatzipanayotou and Phoebe Koundouri: Tradable Permits vs Ecological Dumping

3.2010 Fabio Antoniou, Panos Hatzipanayotou and Phoebe Koundouri: Second Best Environmental Policies under Uncertainty

4.2010 Carlo Carraro, Enrica De Cian and Lea Nicita: Modeling Biased Technical Change. Implications for Climate Policy

5.2010 Luca Di Corato: Profit Sharing under the threat of Nationalization

6.2010 Masako Ikefuji, Jun-ichi Itaya and Makoto Okamura: Optimal Emission Tax with Endogenous Location Choice of Duopolistic Firms

7.2010 Michela Catenacci and Carlo Giupponi: Potentials and Limits of Bayesian Networks to Deal with Uncertainty in the Assessment of Climate Change Adaptation Policies

8.2010 Paul Sarfo-Mensah and William Oduro: Changes in Beliefs and Perceptions about the Natural Environment in the Forest-Savanna Transitional Zone of Ghana: The Influence of Religion

9.2010 Andrea Boitani, Marcella Nicolini and Carlo Scarpa: Do Competition and Ownership Matter? Evidence from Local Public Transport in Europe

10.2010 Helen Ding and Paulo A.L.D. Nunes and Sonja Teelucksingh: European Forests and Carbon Sequestration Services: An Economic Assessment of Climate Change Impacts

11.2010 Enrico Bertacchini, Walter Santagata and Giovanni Signorello: Loving Cultural Heritage Private Individual Giving and Prosocial Behavior

12.2010 Antoine Dechezleprêtre, Matthieu Glachant and Yann Ménière: What Drives the International Transfer of Climate Change Mitigation Technologies? Empirical Evidence from Patent Data

13.2010 Andrea Bastianin, Alice Favero and Emanuele Massetti: Investments and Financial Flows Induced by Climate Mitigation Policies

14.2010 Reyer Gerlagh: Too Much Oil

15.2010 Chiara Fumagalli and Massimo Motta: A Simple Theory of Predation

16.2010 Rinaldo Brau, Adriana Di Liberto and Francesco Pigliaru: Tourism and Development: A Recent Phenomenon Built on Old (Institutional) Roots?

17.2010 Lucia Vergano, Georg Umgiesser and Paulo A.L.D. Nunes: An Economic Assessment of the Impacts of the MOSE Barriers on Venice Port Activities

18.2010 ZhongXiang Zhang: Climate Change Meets Trade in Promoting Green Growth: Potential Conflicts and Synergies

19.2010 Elisa Lanzi and Ian Sue Wing: Capital Malleability and the Macroeconomic Costs of Climate Policy

20.2010 Alberto Petrucci: Second-Best Optimal Taxation of Oil and Capital in a Small Open Economy

21.2010 Enrica De Cian and Alice Favero: Fairness, Credibility and Effectiveness in the Copenhagen Accord: An Economic Assessment

22.2010 Francesco Bosello: Adaptation, Mitigation and "Green" R\&D to Combat Global Climate Change. Insights From an Empirical Integrated Assessment Exercise

23.2010 Jean Tirole and Roland Bénabou: Individual and Corporate Social Responsibility

24.2010 Cesare Dosi and Michele Moretto: Licences, "Use or Lose" Provisions and the Time of Investment

25.2010 Andrés Rodríguez-Pose and Vassilis Tselios (Ixxxvi): Returns to Migration, Education, and Externalities in the European Union

26.2010 Klaus Desmet and Esteban Rossi-Hansberg (Ixxxvi): Spatial Development

27.2010 Massimiliano Mazzanti, Anna Montini and Francesco Nicolli: Waste Generation and Landfill Diversion Dynamics: Decentralised Management and Spatial Effects

28.2010 Lucia Ceccato, Valentina Giannini and Carlo Gipponi: A Participatory Approach to Assess the Effectiveness of Responses to Cope with Flood Risk

29.2010 Valentina Bosetti and David G. Victor: Politics and Economics of Second-Best Regulation of Greenhous Gases: The Importance of Regulatory Credibility

30.2010 Francesca Cornelli, Zbigniew Kominek and Alexander Ljungqvist: Monitoring Managers: Does it Matter?

31.2010 Francesco D'Amuri and Juri Marcucci: "Google it!" Forecasting the US Unemployment Rate with a Google Job Search index

32.2010 Francesco Bosello, Carlo Carraro and Enrica De Cian: Climate Policy and the Optimal Balance between Mitigation, Adaptation and Unavoided Damage 
GC

GC

GC

GC

GC

GC

GC

GC
33.2010 Enrica De Cian and Massimo Tavoni: The Role of International Carbon Offsets in a Second-best Climate Policy: A Numerical Evaluation

34.2010 ZhongXiang Zhang: The U.S. Proposed Carbon Tariffs, WTO Scrutiny and China's Responses

35.2010 Vincenzo Denicolò and Piercarlo Zanchettin: Leadership Cycles

36.2010 Stéphanie Monjon and Philippe Quirion: How to Design a Border Adjustment for the European Union Emissions Trading System?

37.2010 Meriem Hamdi-Cherif, Céline Guivarch and Philippe Quirion: Sectoral Targets for Developing Countries: Combining "Common but Differentiated Responsibilities" with "Meaningful participation"

38.2010 G. Andrew Karolyi and Rose C. Liao: What is Different about Government-Controlled Acquirers in CrossBorder Acquisitions?

39.2010 Kjetil Bjorvatn and Alireza Naghavi: Rent Seekers in Rentier States: When Greed Brings Peace

40.2010 Andrea Mantovani and Alireza Naghavi: Parallel Imports and Innovation in an Emerging Economy

41.2010 Luke Brander, Andrea Ghermandi, Onno Kuik, Anil Markandya, Paulo A.L.D. Nunes, Marije Schaafsma and Alfred Wagtendonk: Scaling up Ecosystem Services Values: Methodology, Applicability and a Case Study

42.2010 Valentina Bosetti, Carlo Carraro, Romain Duval and Massimo Tavoni: What Should We Expect from Innovation? A Model-Based Assessment of the Environmental and Mitigation Cost Implications of Climate-Related R\&D

43.2010 Frank Vöhringer, Alain Haurie, Dabo Guan,Maryse Labriet, Richard Loulou, Valentina Bosetti, Pryadarshi R. Shukla and Philippe Thalmann: Reinforcing the EU Dialogue with Developing Countries on Climate Change Mitigation

44.2010 Angelo Antoci, Pier Luigi Sacco and Mauro Sodini: Public Security vs. Private Self-Protection: Optimal Taxation and the Social Dynamics of Fear

45.2010 Luca Enriques: European Takeover Law: The Case for a Neutral Approach

46.2010 Maureen L. Cropper, Yi Jiang, Anna Alberini and Patrick Baur: Getting Cars Off the Road: The CostEffectiveness of an Episodic Pollution Control Program

47.2010 Thomas Hellman and Enrico Perotti: The Circulation of Ideas in Firms and Markets

48.2010 James Dow and Enrico Perotti: Resistance to Change

49.2010 Jaromir Kovarik, Friederike Mengel and José Gabriel Romero: (Anti-) Coordination in Networks

50.2010 Helen Ding, Silvia Silvestri, Aline Chiabai and Paulo A.L.D. Nunes: A Hybrid Approach to the Valuation of Climate Change Effects on Ecosystem Services: Evidence from the European Forests

51.2010 Pauline Grosjean (Ixxxvii): A History of Violence: Testing the 'Culture of Honor' in the US South

52.2010 Paolo Buonanno and Matteo M. Galizzi (Ixxxvii): Advocatus, et non latro? Testing the Supplier-InducedDemand Hypothesis for Italian Courts of Justice

53.2010 Gilat Levy and Ronny Razin (Ixxxvii): Religious Organizations

54.2010 Matteo Cervellati and Paolo Vanin (Ixxxvii): "Thou shalt not covet ...": Prohibitions, Temptation and Moral Values

55.2010 Sebastian Galiani, Martín A. Rossi and Ernesto Schargrodsky (Ixxxvii): Conscription and Crime: Evidence from the Argentine Draft Lottery

56.2010 Alberto Alesina, Yann Algan, Pierre Cahuc and Paola Giuliano (Ixxxvii): Family Values and the Regulation of Labor

57.2010 Raquel Fernández (Ixxxvii): Women's Rights and Development

58.2010 Tommaso Nannicini, Andrea Stella, Guido Tabellini, Ugo Troiano (Ixxxvii): Social Capital and Political Accountability

59.2010 Eleonora Patacchini and Yves Zenou (Ixxxvii): Juvenile Delinquency and Conformism

60.2010 Gani Aldashev, Imane Chaara, Jean-Philippe Platteau and Zaki Wahhaj (Ixxxvii): Using the Law to Change the Custom

61.2010 Jeffrey Butler, Paola Giuliano and Luigi Guiso (Ixxxvii): The Right Amount of Trust

62.2010 Valentina Bosetti, Carlo Carraio and Massimo Tavoni: Alternative Paths toward a Low Carbon World

63.2010 Kelly C. de Bruin, Rob B. Dellink and Richard S.J. Tol: International Cooperation on Climate Change Adaptation from an Economic Perspective

(Ixxxvi) This paper was presented at the Conference on "Urban and Regional Economics" organised by the Centre for Economic Policy Research (CEPR) and FEEM, held in Milan on 12-13 October 2009.

(Ixxxvii) This paper was presented at the Conference on "Economics of Culture, Institutions and Crime" organised by SUS.DIV, FEEM, University of Padua and CEPR, held in Milan on January 20-22 2010. 